\title{
BERNFORSCHUNGSZENTRU
}

\author{
KARLSRUHE
}

November 1977

KFK 2470

Institut für Angewandte Kernphysik

\section{Experimental Studies of Hexadecapole Motion in Spherical Nuclei}

A. Hanser, H. Faust, H. Klewe-Nebenius,

H. Rebel, J. Buschmann, H. J. Gils

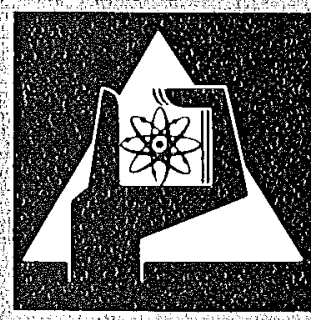

GESELLSCHAFT

FUR

KERNFORSCHUNG M.B.H.

KARLSRUHE 
Als Manuskript vervielfältigt

Für diesen Bericht behalten wir uns alle Rechte vor

GESELLSCHAFT FÜR KERNFORSCHUNG M. B. H. KARLSRUHE 
KERNFORSCHUNGSZENTRUM KARLSRUHE

KFK 2470

Institut für Angewandte Kernphysik

Experimental Studies of Hexadecapole Motion in Spherical Nuclei

A. Hanser, H. Faust ${ }^{+}, H$. Klewe-Nebenius ${ }^{++}, H$. Rebel, J. Buschmann and H.J. Gils

+ Physikalisches Institut der Universität Heidelberg

++ Kernforschungszentrum Karlsruhe, Institut für Radiochemie

Gesel1schaft für Kernforschung m.b.H., Karlsruhe 

The $0^{+} \rightarrow 4_{1}^{+}$hexadecapole transitions in ${ }^{60} \mathrm{Ni}$ and ${ }^{140} \mathrm{Ce}$ have experimentally been investigated by means of $\alpha$-particle scattering as well as by spectroscopy of the electromagnetic decay of the $4_{1}^{+}$states. In the case of ${ }^{60} \mathrm{Ni}$ an upper 1 imit of $1 \times 10^{-7}$ was found for the branching of the E4 and E2 cascade decay of the $4_{1}^{+}$state by conversion electron spectroscopy. It corresponds to an enhancement factor $G_{4}<9.0$ s.p.u., while the $\alpha$-particle scattering measurements result in $G_{4}=(5.5 \pm 0.8)$ s.p.u.. In ${ }^{140} \mathrm{Ce}$ the $4_{1}^{+} \rightarrow 0^{+}$ cross-over $\gamma$-decay has been observed with an enhancement of $G_{4}=(11.8 \pm 0.7)$ s.p.u. in very good agreement with the value $G_{4}=(13 \pm 2)$ s.p.u. from the $\alpha$-particle scattering experiments. The evaluation of the $\alpha$-particie scattering cross sections is based on a specific reaction model (folding model). The experimental results from the direct $\left(4_{1}^{+} \rightarrow 0^{+}\right)$decay are considered to be an empirical test of model dependence of the procedures extracting $L=4$ transition rates from $\alpha$-particle scattering. Compiling several similar results the consistency of the methods applied as well as the evidence and some implications of hexadecapole motion in spherical nuclei are briefly discussed. 


\section{ZUSAMMENFASSUNG:}

Die $0^{+} \rightarrow 4_{1}^{+}$Hexadekapol-Obergänge in ${ }^{60} \mathrm{Ni}$ und ${ }^{140} \mathrm{Ce}$ wurden experimente11 sowohi durch $\alpha$-Teilchenstreuung als auch durch Beobachtung des elektromagnetischen Zerfalls der $4_{1}^{+}$-Zustände untersucht. Im Falle von ${ }^{60} \mathrm{Ni}$ wurde mittels Konversionselektronenspektroskopie eine obere Grenze von $1 \times 10^{-7}$ für das Verzweigungsverhältnis von E4- und E2-(Kaskaden)-Zerfall gefunden. Dies entspricht einem $L=4$ "Enhancement" $G_{4}<9.0$ s.p.u., während man aus den $\alpha$-Teilchen-Streuexperimenten den Wert $G_{4}=(5.5 \pm 0.8)$ s.p.u. gewinnt. In ${ }^{140}$ Ce konnte der $4_{1}^{+} \rightarrow 0^{+} \gamma$-Obergang mit einer kollektiven Verstärkung von $G_{4}=(11.8 \pm 0.7) \mathrm{s} . \mathrm{p} . u$. beobachtet werden, in sehr guter Obereinstimmung mit dem Wert $G_{4}=(13 \pm 2)$ s.p.u. aus der $\alpha$-Teilchenstreuung. Die Auswertung der Wirkungsquerschnitte für die $\alpha$-Teilchenstreuung basiert auf einem speziellen Reaktionsmode11 (Faltungsmode11). Die Resultate der direkten experimentellen Beobachtung des $4_{1}^{+} \rightarrow 0^{+}$Zerfalls sind ein empirischer Test auf die Modellabhängigkeit der Verfahren, mit denen $L=4$. Obergangsraten aus der $\alpha$-Teilchenstreuung gewonnen werden. Zusammen mit einigen anderen ähnlichen Ergebnissen werden die Konsistenz der Methoden sowie die Evidenz und einige Implikationen der Hexadekapol-Bewegung in sphärischen Kernen kurz diskutiert. 
1. INTRODUCTION 1

2. SEARCH FOR THE $4_{1}^{+} \rightarrow 0^{+}$CROSSOVER TRANSITIONS IN 2 ${ }^{60}$ NI AND ${ }^{140} \mathrm{CE}$

3. INELASTIC $\alpha$-PARTICLE SCATTERING

$\begin{array}{ll}\text { 4. DISCUSSION } & 13\end{array}$

5. CONCLUSIONS 16

APPENDIX: EXPERIMENTAL DETAILS

A DETAILS OF THE CONVERSION ELECTRON MEASUREMENT CONCERNING 17

THE $4_{1}^{+} \rightarrow 0^{+}$TRANSITION STRENGTH IN ${ }^{60} \mathrm{NI}$

A-1 The Spectrometer $\quad 17$

A-2 The ${ }^{60}$ Co Source 19

A-3 The Experimental Procedure 20

B DETAILS OF THE MEASUREMENT OF THE $4_{1}^{+} \rightarrow 0^{+} \gamma$-RAY TRANSITION 21 IN ${ }^{140}$ CE

B-1 Detection Device 21

B-2 Peak Analysis 22

B-3 Check of the Assignment of the $2083 \mathrm{keV}$ Peak 23

B-4 Determination of the Intensity Ratio 26 $I_{\gamma}(2083 \mathrm{keV}) / \mathrm{I}_{\gamma}(487 \mathrm{keV})$

B-5 Calculation of the Enhancement and the Main Partial 27 Errors

B-6 Additional Spectroscopic Results 28

C DETAILS OF THE $\left(\alpha, \alpha^{\prime}\right)$ SCATTERING MEASUREMENTS 29

C-1 Experimental Arrangement 29

$\begin{array}{ll}\mathrm{C}-2 \text { The }{ }^{60} \mathrm{Ni} \text { Experiment } & 29\end{array}$

C-3 The ${ }^{140} \mathrm{Ce}$ Experiment 29

$\begin{array}{ll}\text { REFERENCES } & 35\end{array}$ 


\section{INTRODUCTION}

From various different experimental and theoretical investigations there is considerable evidence for the presence of hexadecapole components in the equilibrium shapes of deformed nuclei both heavy and light. The question of a possible hexadecapole motion in spherical and quasispherical nuclei, however, has not been studied very extensively, though there are various theoretical considerations (Kuo and Brown 1966, Goswami and Lin 1972) and many indications in different types of experimental results. Rather unambiguous information, to what extent a hexadecapole vibrational mode is present in spherical nuclei, is provided by measurements of the collectivity of the "two(quadrupole) phonon" $4_{1}^{+}$states with respect to E4 transitions. Such additional hexadecapole amplitude is giving rise to enhanced $L=4$ transition rates. Inelastic electron-, proton- and $\alpha$-particle scattering have been proved to be very fruitful methods looking for such $L=4$ contributions. In particular, inelastic $\alpha$-particle scattering in the $100 \mathrm{MeV}$ region (Tamura 1965, Rebel et al. 1972 a, Rebel et a1. 1972 b) is extremely sensitive to magnitude and phase of $L=4$ transition amplitudes. Recently, improved and nearly mode 1 independent procedures have been worked out (Rebel 1976) for extracting reliable values of the transition rates from $\alpha$-particle scattering. Some deficiencies of previous procedures (Bernstein 1969) have been removed, by which the rates, in particular of higher multipolarities, had generally been underestimated. This now enables reasonable comparisons of electromagnetic and $\alpha$-particle scattering transition rates. It should be emphasized that the transition rates in both cases are not necessarily equal. The $\alpha$-particle scattering rates (obtained at energies well above the Coulomb barrier) are isoscalar and involve protons and neutrons equally whereas electromagnetic transitions involve dominantly the protons. Significant differences between the two types of transition rates would reveal interesting nuclear structure information. But for light and medium heavy nuclei differences between charge and mass transitions are assumed to be unlikely so that here a comparison of the found values would rather be a test for the remaining model dependence of the procedure analysing the scattering data. We note that even electron scattering results are in most cases not completely free from model dependence due to specific assumptions (e.g. phenomenological parametrization of the transition densities) in the particular analysis.

Submitted: $13 \cdot 10 \cdot 1977$ 
From this it appears to be desirable to investigate the transitions in the most direct way by observing the electromagnetic decay of the excited states. For $4_{1}^{+} \rightarrow 0^{+}$transitions this is in most cases a very difficult task since an E2 cascade which is several orders of magnitude stronger competes with such an E4 transition. But in favourable cases it has been possible to observe directly electromagnetic $4_{1}^{+} \rightarrow 0^{+}$cross over transitions (Signorini and Morinaga 1972, Hanser et a1. 1975) revealing unambiguously the presence of hexadecapole motion in the $4_{1}^{+}$states of $\mathrm{Pb}$ nuclei.

In this paper we report on similar experiments for the $4_{1}^{+} \rightarrow 0^{t}$ transitions in ${ }^{60} \mathrm{Ni}$ and ${ }^{140} \mathrm{Ce}$. In these cases from previous investigations (Morinaga and Takahashi 1959, Crannel et al. 1961, Rebel et al. 1972 a, Baker and Tickle 1972, Pitthan 1973) enhanced hexadecapole transitions are expected to be possibly observable in the direct electromagnetic decay of the $4_{1}^{+}$states. In addition to the electromagnetic studies and supplementing previous results (Gils and Rebel 1975b, Rebel 1976) we investigated also the excitation of the $4_{1}^{+}$states by inelastic scattering of $104 \mathrm{MeV} \alpha$-particles and extracted the isoscalar $L=4$ transition rates by procedures which are extensively described elsewhere (Rebel 1976). Comparing the results of the different methods the main aspect is given by the question of consistency of the results. In cases where no electromagnetic results are available it has to be discussed to what extent $\alpha$-particle scattering results of $L=4$ transitions can be assumend to be quantitatively reliable. Compiling similar results for nuclei near closed shells we discuss the evidence and some implications of hexadecapole motion in spherical nuclei.

2. SEARCH FOR THE $4_{1}^{+} \rightarrow 0^{+}$CROSSOVER TRANSITIONS IN ${ }^{60} \mathrm{Ni}$ AND ${ }^{140} \mathrm{Ce}$

In order to observe the weak E4 crossover transitions by a semiconductor detector, one has to provide a suppression of the sum peak resulting from simultaneous detection of the two dominating cascade transitions as well as a reduction of pile-up events due to the very high counting rates at lower energies, which strongly increase the continuous background underlying the weak $\gamma$-ray peak. In a preceding experiment we succeeded to detect an E4 crossover transition in ${ }^{202} \mathrm{~Pb}$ (Hanser et al. 1975) by measuring the conversion electrons by means of a special electron spectrometer ("mini orange"). The "mini orange" spectrometer consists of a $\mathrm{Si}(\mathrm{Li})$ detector and a filter 
of several approximately wedge shaped permanent magnets $\left(\mathrm{Sm} \mathrm{Co}_{5}\right)$ producing a toroidal field between the magnets. With a particular configuration of the magnets and of the total arrangement the transmission is suppressed in the low energy part of the spectrum by several orders of magnitude and peaks in the region of particular interest. Details of this spectrometer type are given elsewhere (van Klinken et a1. 1975). The condition favouring the use of such a spektrometer and some advantages of looking for the conversion electrons rather than for the $\gamma$-rays - in spite of a small conversion coefficient - are discussed by Hanser et al. (1975).

For the search of the conversion electrons of the $2505 \mathrm{keV} 4_{1}^{+} \rightarrow 0^{+}$transition in ${ }^{60} \mathrm{Ni}$ the mini orange system has been improved using a "double orange" set up (see fig. 1). In this arrangement the background from looping low energy electrons and from Compton electrons is strongly reduced. (See appendix, sect. A.)

The transmission curve of the complete system shown in fig. 2 has been

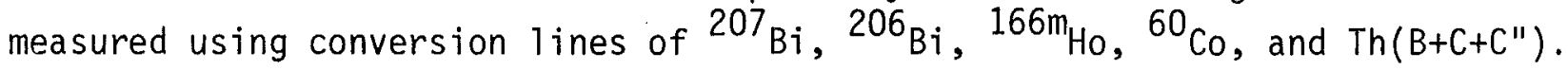
The absolute scale of the transmission curve has been determined by use of a calibrated ${ }^{207} \mathrm{Bi}$ source with and without the magnetic system, respectively, in a defined geometry. The dashed parts of the curve originate from a (less reliable) evaluation of the continuous $B^{-}$-spectrum of $T h\left(B+C+C^{\prime \prime}\right)$, but are confirmed by several points from adjacent conversion lines.

For the measurements a ${ }^{60} \mathrm{Co}$ source of $\sim 3 \mathrm{mCi}$ was produced by activating a $2 \mathrm{mg} / \mathrm{cm}^{2}$ thick Co-foil for about 3 weeks within a neutron flux of $28 \times 10^{13} \mathrm{n} / \mathrm{cm}^{2} \cdot \mathrm{s}$ in the Karlsruhe Research Reactor. The electron spectrum recorded during a period of 32 days is shown in fig. 1. A11 peaks are labelled with the corresponding $\gamma$-ray transition energies. Besides the weak $2_{2}^{+} \rightarrow 0^{+}$transition of $2158 \mathrm{keV}$ only the 3 possible pile up peaks of the E2 cascade shifted to lower energies by twice the K-binding energy of $\mathrm{Ni}$ are visible in the high energy part of the spectrum. The expected position of the $2505 \mathrm{keV} E 4$ transition is indicated by an arrow. Since there is no peak visible which can be assigned to the E4 transition, we deduced an upper limit for the $\gamma$-ray branching ratio of

$$
\frac{I_{\gamma}(2505 \mathrm{keV})}{I_{\gamma}(1173 \mathrm{keV})}<1 \times 10^{-7}
$$

using the separately measured source strength, the known absolute efficiency of the electron spectrometer, and a conversion coefficient for the $2505 \mathrm{keV}$ E4 transition of $\alpha_{K}=5.6 \times 10^{-5}$. This value has been extrapolated from the tables 


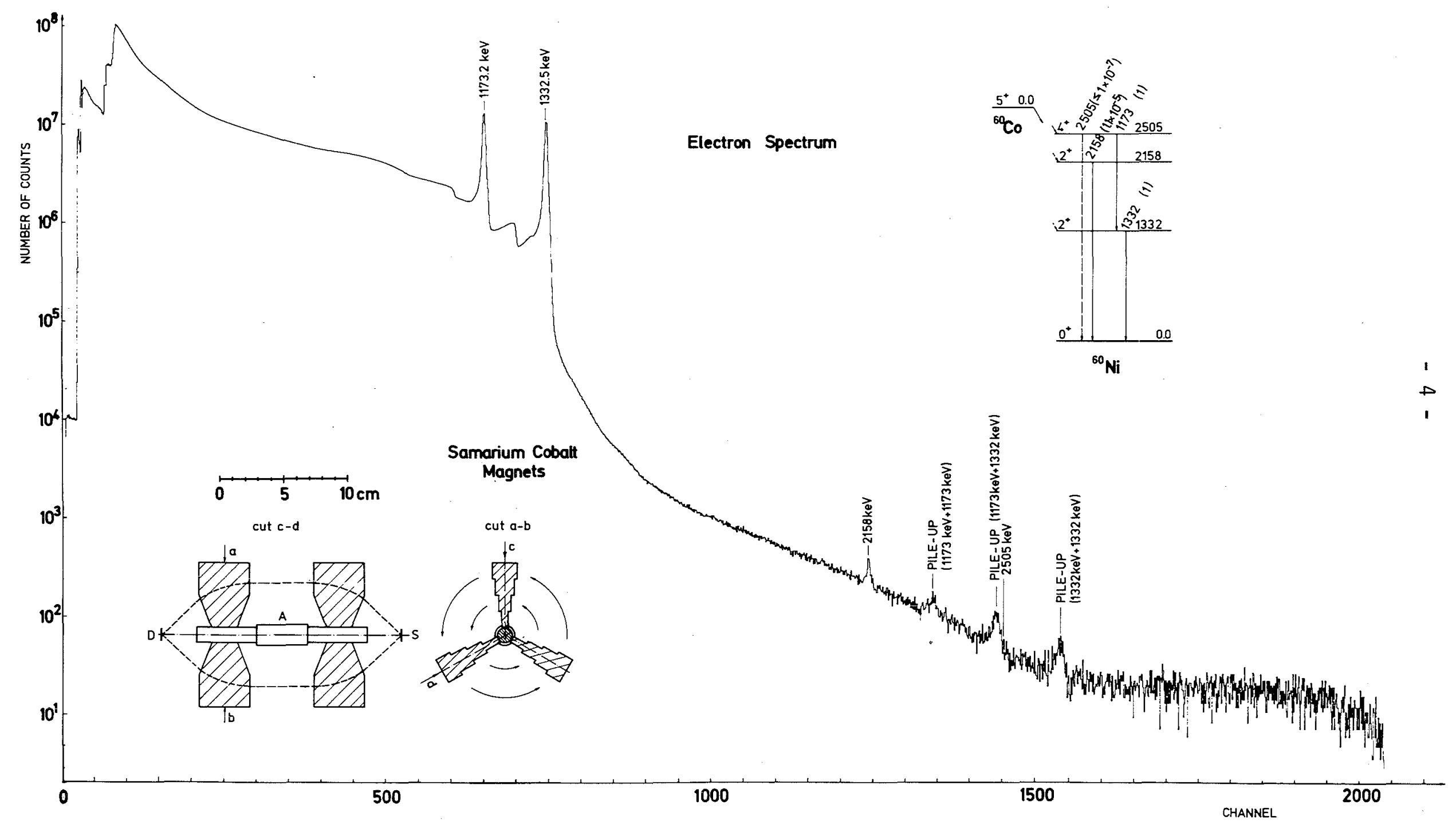

Fig. 1: Electron spectrum of a $3 \mathrm{mC} i{ }^{60}$ Co source measured for 32 days. The peaks are labelled with the respective $\gamma$-ray energies from which they differ by the K-binding energy of $60 \mathrm{Ni}$. The pile-up peaks of the E2 cascade (shifted from the respective $\gamma \gamma$-pile-up-peaks by twice the binding energy) show the typical broadening. The insets show schematically the "double-orange" set-up and the relevant part of the 60Ni level scheme, respectively. 
of Sliv and Band (1965). Using the life-time of $(4.7 \pm 0.7$ ) ps (Ivanov et al. 1975) for the ${ }^{60} \mathrm{Ni} 4_{1}^{+}$-level, an upper 1 imit for the $\mathrm{E} 4$ enhancement of

$$
G_{4}<9.0 \text { s.p.u. }
$$

is obtained.

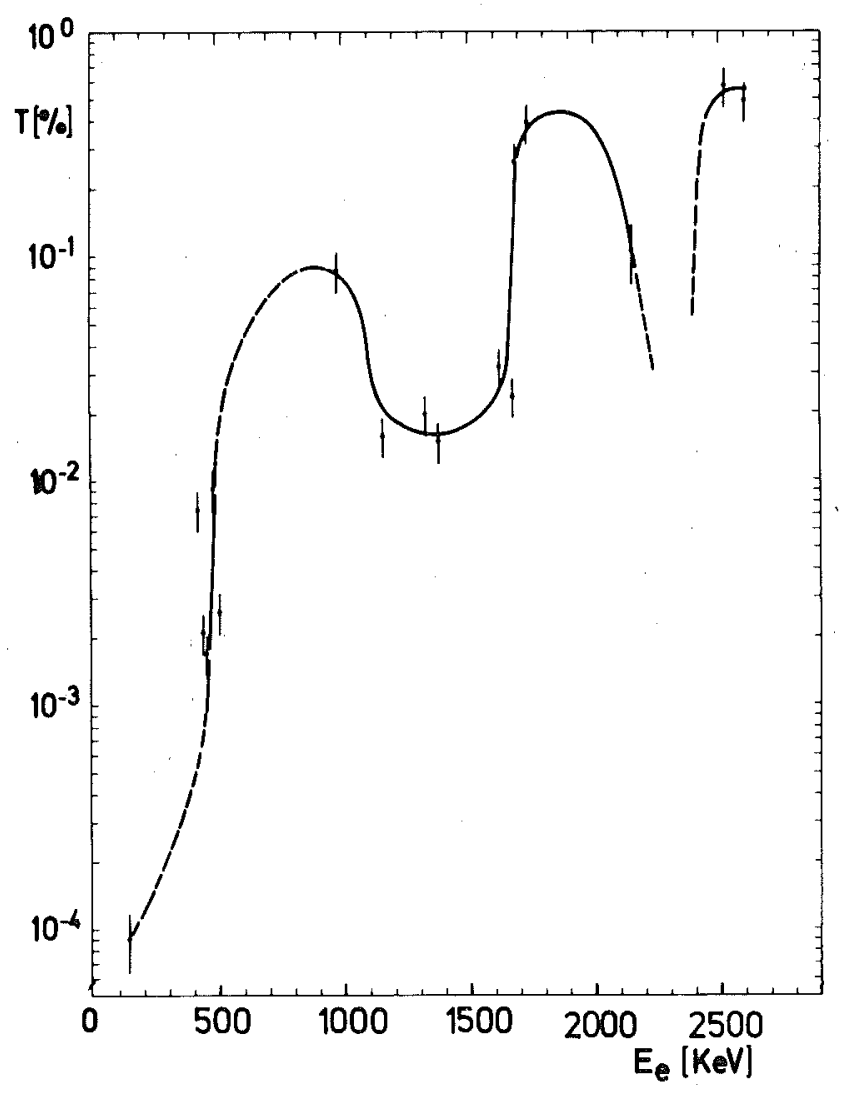

Fig. 2 Transmission curve of the "double-orange" set-up measured with several sources (see text). The transmission in the dashed regions has been evaluated from the continuous $\beta^{-}$-spectrum of $\mathrm{Th}\left(B+C+C^{\prime \prime}\right)$ taking into account the deformation of the spectral shape by backscattering of electrons from the detector surface. 
In the case of ${ }^{140} \mathrm{Ce}$ the conversion electron spectroscopy is less favourable since the $\beta$-continuum from the $\beta$-decay of ${ }^{140} \mathrm{La}$ is interfering. Therefore, we looked for the $4_{1}^{+} \rightarrow 0^{+} \gamma$-rays and applied the method previously used by Signorini and Morinaga (1972) in the case of ${ }^{204} \mathrm{~Pb}$, reducing the intensity of the E2 cascade and consequently the sum peak by a lead absorber. A $5 \mathrm{~cm}$ thick lead absorber arranged halfway between the source and a $\mathrm{Ge}(\mathrm{Li})$ detector (source-detector distance $80 \mathrm{~cm}$ ) reduced the intensity of the $487 \mathrm{keV}$ $4_{1}^{+} \rightarrow 2_{1}^{+}$transition by a factor of about 5000 while the searched $4_{1}^{+} \rightarrow 0^{+}$ $\gamma$-rays which would have an energy of $2083 \mathrm{keV}$ were reduced only by a factor of 13. The Ge(Li)-detector was surrounded by a NaI (TI) anticompton annulus (20 $\mathrm{cm} \emptyset$ and $20 \mathrm{~cm}$ in length) in order to improve the peak to background ratio. Additional improvement of the peak to background ratio was obtained by an electronical pile-up rejection system which was able to resolve pulse pairs separated by more than $150 \mathrm{~ns}$, strongly suppressing pile-up counts of the continuum (but not of the sum peak which results from events coinciding in time). The energy dependence of the efficiency of the total arrangement has been measured by means of the $\gamma$-rays of ${ }^{56}$ Co using the intensities reported by Katou (1975) and well known $\gamma$-rays of the ${ }^{140}$ La decay. The absolute efficiency has been determined by an intensity calibrated ${ }^{60}$ Co source (see fig. 3). Since the assignment of the expected $4_{1}^{+} \rightarrow 0^{+}$transition could be based only on the observed transition energy and on the half-life an accurate energy calibration was necessary and has been performed with ${ }^{66} \mathrm{Ga}$ and ${ }^{56} \mathrm{Co}$ sources.

The ${ }^{140} \mathrm{La}$ sources used have been prepared by irradiating two samples of about $8 \mathrm{mg} \mathrm{LaO} 2$ powder for one hour in a thermal neutron flux of about $8 \times 10^{13} \mathrm{n} / \mathrm{cm}^{2} \cdot \mathrm{s}$ (of the Karlsruhe Research Reactor). Starting with an initial activity of about $7 \mathrm{mCi} \gamma$-ray spectra have been recorded for about 4 periods of the half-life adding the second source after 1 half-life, thus increasing the contributions of the later counting periods to the counting statistics. In fig. 4 one of the recorded spectra is displayed in a logarithmic scale together with the interesting section around $2083 \mathrm{keV}$ plotted in a linear scale. For an assignment of the clearly visible peak to the $4_{1}^{+} \rightarrow 0^{+}$transition in ${ }^{140} \mathrm{Ce}$ we have determined the energy difference between the $2083 \mathrm{keV}$ and the $1596 \mathrm{keV}$ peak representing the $2_{1}^{+} \rightarrow 0^{+}$transition as precisely 
as possible. After correction for the small recoil effects we compared it to the energy of the $4_{1}^{+} \rightarrow 2_{1}^{+}$E2 transition given in the literature (from values quoted by Peker et a . (1974) $(487.03 \pm 0.02) \mathrm{keV}$ was adopted). The comparison leads to a difference of $(0.10 \pm 0.10) \mathrm{keV}$. The half life of the $2083 \mathrm{keV}$ peak has been checked by comparison with well known transitions following the ${ }^{140}$ La decay. From the small but clearly visible pile-up peak at $3192 \mathrm{keV}$ originating from two simultaneously detected $1596 \mathrm{keV} \gamma$-rays the contribution of pile-up events to the $2083 \mathrm{keV}$ peak is estimated to be $0.2 \%$. As the pile-up effect is not independent from the involved $\gamma$-ray energies a better estimate is provided by the upper limit of the not visible $(1596$ - 816) keV pile-up peak which was estimated to be $<0.7 \%$. Thus, we adopt an upper limit of $1 \%$ for the $(1596$ - 487) keV pile-up contribution. The contribution from the sum coincidence was calculated from the absolute peak efficiencies to be $<7 \times 10^{-5}$.

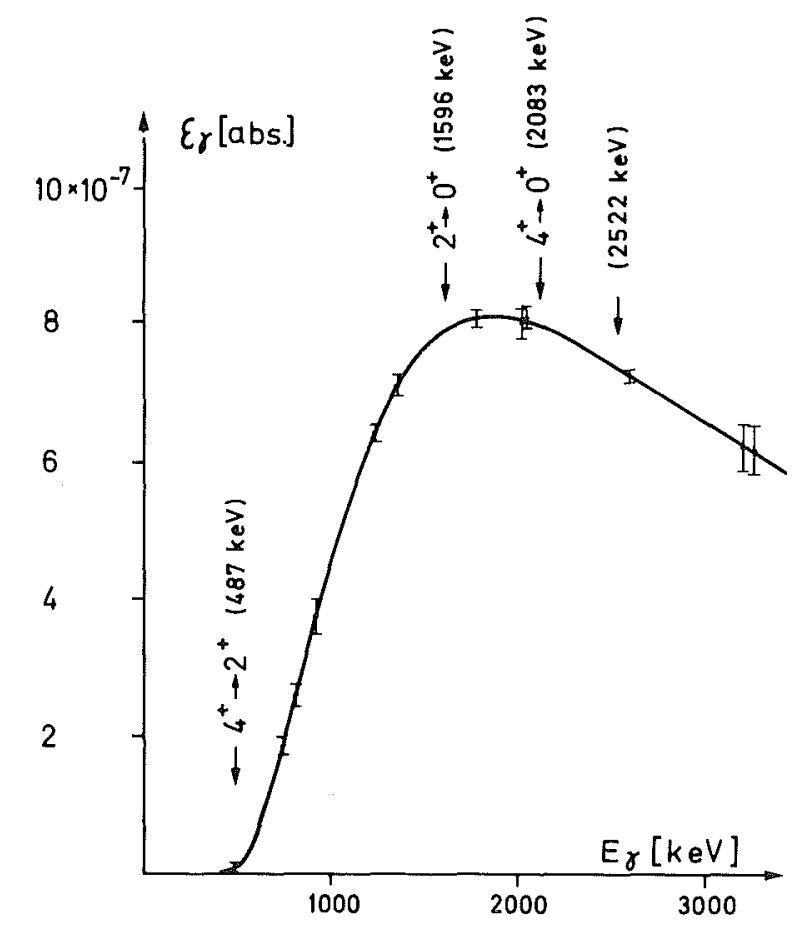

Fig. 3 Absolute efficiency of the $\gamma$-ray spectrometer including a lead absorber, Compton suppression, and pile-up-rejection. The positions of the relevant transitions are indicated. The error bars are those for relative efficiency. 

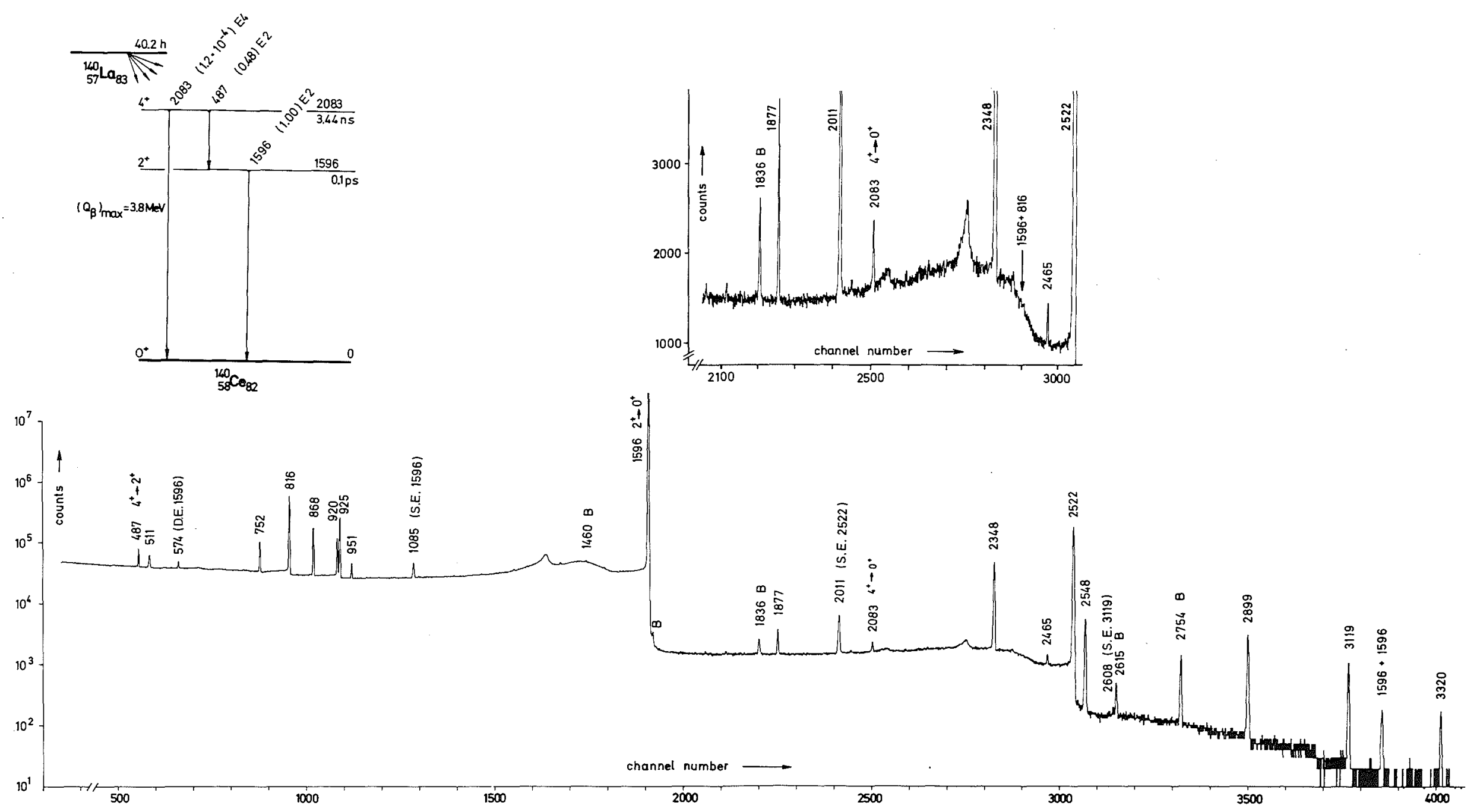

Fig. 4 Measured $\gamma$-ray spectrum of a neutron activated La sample. The inset shows a linearly plotted section of the region of interest. 
The corrected intensity of the observed $4_{1}^{+} \rightarrow 0^{+}$peak results in a branching ratio of

$$
\frac{I_{\gamma}(2083 \mathrm{keV})}{I_{\gamma}(487 \mathrm{keV})}=(2.54 \pm 0.15) \times 10^{-4} \text {. }
$$

This ratio was obtained by combining the ratio $I_{\gamma}(2083) / I_{\gamma}(2522)$ which we have measured with the arrangement described above and the ratio $I_{\gamma}(2522) / I_{\gamma}(487)$ which we have determined precisely in a separate measurement wi thout leadabsorber. The $2522 \mathrm{keV} \gamma$-ray follows the 140 La decay with an intensity sufficient for a precise determination (see fig. 4). Further details of the experimental procedure and more detailed spectroscopic results can be found in the appendix, sect. B.

With the experimental half-life of $(3.44 \pm 0.03)$ ns for the $4_{1}^{+}$level of ${ }^{140} \mathrm{Ce}$ adopted from several results reported by Peker et al. (1974) an enhancement of

$$
G_{4}=(11.8 \pm 0.7) \text { s.p.u. }
$$

for the observed E4 transition is obtained.

\section{INELASTIC $\alpha$-PARTICLE SCATTERING}

The present $\left(\alpha, \alpha^{\prime}\right)$ scattering experiments aimed at sufficiently precise data of the $4_{1}^{+}$differential cross sections. In the case of $60 \mathrm{Ni}$ the experiments continue previous studies of elastic and inelastic scattering of $104 \mathrm{MeV}$ a-particles on even $\mathrm{Ni}$ isotopes (Rebel et a1. 1972 a) and improve the accuracy of the $4_{1}^{+}$cross section. The measurements used the scattering facilities at the $104 \mathrm{MeV}$ a-particle beam at the Karlsruhe Isochronous Cyclotron. Details of the experimental set-up and procedures are given in the appendex, sect. A. The measured ${ }^{60} \mathrm{Ni}\left(\alpha, \alpha^{\prime}\right)$ cross sections and the results of a coupled channel analysis are displayed in fig. 5 .

The basis of the analysis more extensively described by Rebel(1976) is briefly sketched for the case of ${ }^{60} \mathrm{Ni}$ in the following:

The density distribution of the ${ }^{60} \mathrm{Ni}$ nucleus has been parametrized by a Fermi distribution with two parameters (halfway radius $c$ and diffuseness a) adopted from electron scattering results (de Jager et al. 1974)

$$
\rho(r-c)=\rho_{0} /(1+\exp ((r-c) / a))
$$


The excitation of the low-lying states is described by a flexible anharmonic vibrational model (Tamura 1966, Rebel et a1. 1972 a) describing surface vibrations in the usual way by

$$
c=c_{0}\left(1+\sum_{\lambda, \mu}^{4} \alpha_{\lambda \mu} \gamma_{\lambda \mu}\right)
$$

up to terms with $\lambda=4$. The transition rates are determined by the "deformation parameters"

$$
\beta_{I I^{\prime}}=\left\langle I^{\prime}|| \alpha_{\lambda} \| I\right\rangle \delta_{I^{\prime} \lambda} \text {, }
$$

and our interest is here focussed to

$$
\beta_{04}=\left\langle 0|| \alpha_{4}|| 4_{1}^{+}\right\rangle \text {. }
$$

The quadrupole matrix element $\beta_{02}$ has been adopted from Coulomb excitation results (Lesser et a.1. 1974). Until recently the E2 rate of the $2_{1}^{+} \rightarrow 4_{1}^{+}$ excitation in ${ }^{60} \mathrm{Ni}$ was known only with considerable uncertainty (Ronsin et a1. 1973). Fortunately, the choice of the matrix element $\beta_{24}$ affects the result for the (actually dominating) hexadecapole transition $0^{+} \rightarrow 4_{1}^{+}$ in a minor way. Most of the coupled channel calculations studying the various sensitivities used the vibrator limit $\beta_{24}=\beta_{02}(=0.22)$; alternative choices (e.g. $\beta_{24} \sim 0.5 \beta_{02}$ ) change the $\beta_{04}$ value required by the fit to the experimental cross sections insignificantly. Using $\beta_{24}$ as a free parameter (in addition to $B_{04}$ ) and fitting the cross sections according to the $\chi^{2} / F$ minimum criterion a best value of $\beta_{24} \sim 0.11$ is favoured.

Specifying the density distribution and nuclear surface as described above the real part of the $\alpha$-particle-nucleus (deformed) optical potential has been generated by a folding procedure:

$$
U_{R}\left(\vec{r}_{\alpha}\right)=\int V_{\text {eff }}\left(\vec{r}-\vec{r}_{\alpha}\right) \cdot \rho(\vec{r}) d^{3} r
$$

A Gaussian $\alpha$-particle bound nucleon effective interaction $V_{e f f}$ has been used (see e.g. Gils et al. 1976) which is well determined by several investigations. In the present cases the imaginary part of the optical potential has been taken to be proportional to the real potential $\left(U_{I} \propto U_{R}\right)$ thus introducing a third free parameter into the analysis. 
The theoretical cross sections calculated with $\beta_{04}=0$ and $\beta_{04}=0.11$ demonstrate the strongsensitivity to $L=4$ contributions (see fig. 5 ). The result of the coupled channel analysis corresponds to $G_{4}=(5.5 \pm 0.8) \mathrm{s} . \mathrm{p} . \mathrm{u}$. for the $0^{+} \rightarrow 4_{1}^{+}$transition in ${ }^{60} \mathrm{Ni}$. We note that the found value $\beta_{24} \sim 0.11$ agrees within $20 \%$ with the result of the recent 1 ife-time measurement of the $4_{1}^{+}$state (Ivanov et a 1. 1975) and leads to a branching of the E4 to E2 decay of about $5 \times 10^{-8}$.

Inelastic $\alpha$-particle scattering from ${ }^{140} \mathrm{Ce}$ has been investigated at $E_{\alpha}=45 \mathrm{MeV}$ by Baker and Tickle(1972). The $G_{4}$ value of $7.8 \mathrm{~s} . p . u$. obtained by Bernstein's procedure (Bernstein 1969) indicates a strong $L=4$ enhancement but disagrees with the electromagnetic results.

Our present experiments at $E_{\alpha}=104 \mathrm{MeV}$ joined to previous studies of elastic scattering (Hauser et a1. 1968) and tried to extend the measurements to inelastic scattering from low-lying states. We used a ${ }^{140}$ Ce oxide target (thickness $480 \mu \mathrm{g} / \mathrm{cm}^{2}{ }^{140} \mathrm{Ce}, 99 \%$ isotopically enriched) which proved to contain considerable amount of carbon(and other elements) from the target fabrication process.

The known cross sections for elastic scattering from ${ }^{16} 0$ (Hauser et a1. 1968) has been used for the determination of the target thickness, the resulting value of which is consistent with elastic scattering results and forwardangle optical model predictions for ${ }^{140} \mathrm{Ce}$. The target contaminants of light elements prevented to measure inelastic scattering at very forward angles, and in general the inelastic peaks of interest had to be separated from dominating contamination peaks by computer processing of the measured spectra (see appendix, sect. A). As a consequence the differential cross sections for inelastic scattering from the $4_{1}^{+}$state could be reliably extracted only for one diffraction oscillation (fig. 6). But due to the strong sensitivity of the $4_{1}^{+}$cross sections to $L=4$ contributions the measured data prove to be sufficiently accurate for a determination of the hexadecapole transition rate. For the same reason the $\beta_{02}$ matrix element could not be extracted from the present data but was adopted from the $2^{+}$half-life quoted by Peker et al. (1974). The coupled channel analys is performed in a similar way as described in the ${ }^{60} \mathrm{Ni}$ case yields a $\mathrm{G}_{4}$-value of $(13 \pm 2)$ s.p.u. in good agreement with our result from $4_{1}^{+} \rightarrow 0^{+} \gamma$-decay. 


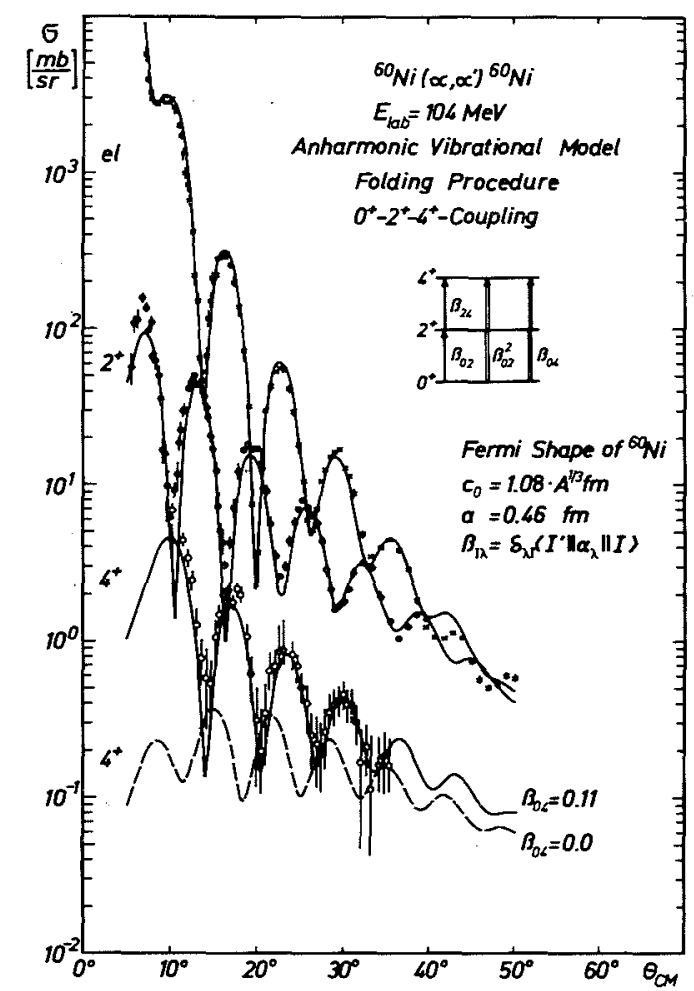

Fig. $5{ }^{60} \mathrm{Ni}\left(\alpha, \alpha^{1}\right)^{60} \mathrm{Ni}$ : Measured differential cross sections and results of the coupled channel analysis.

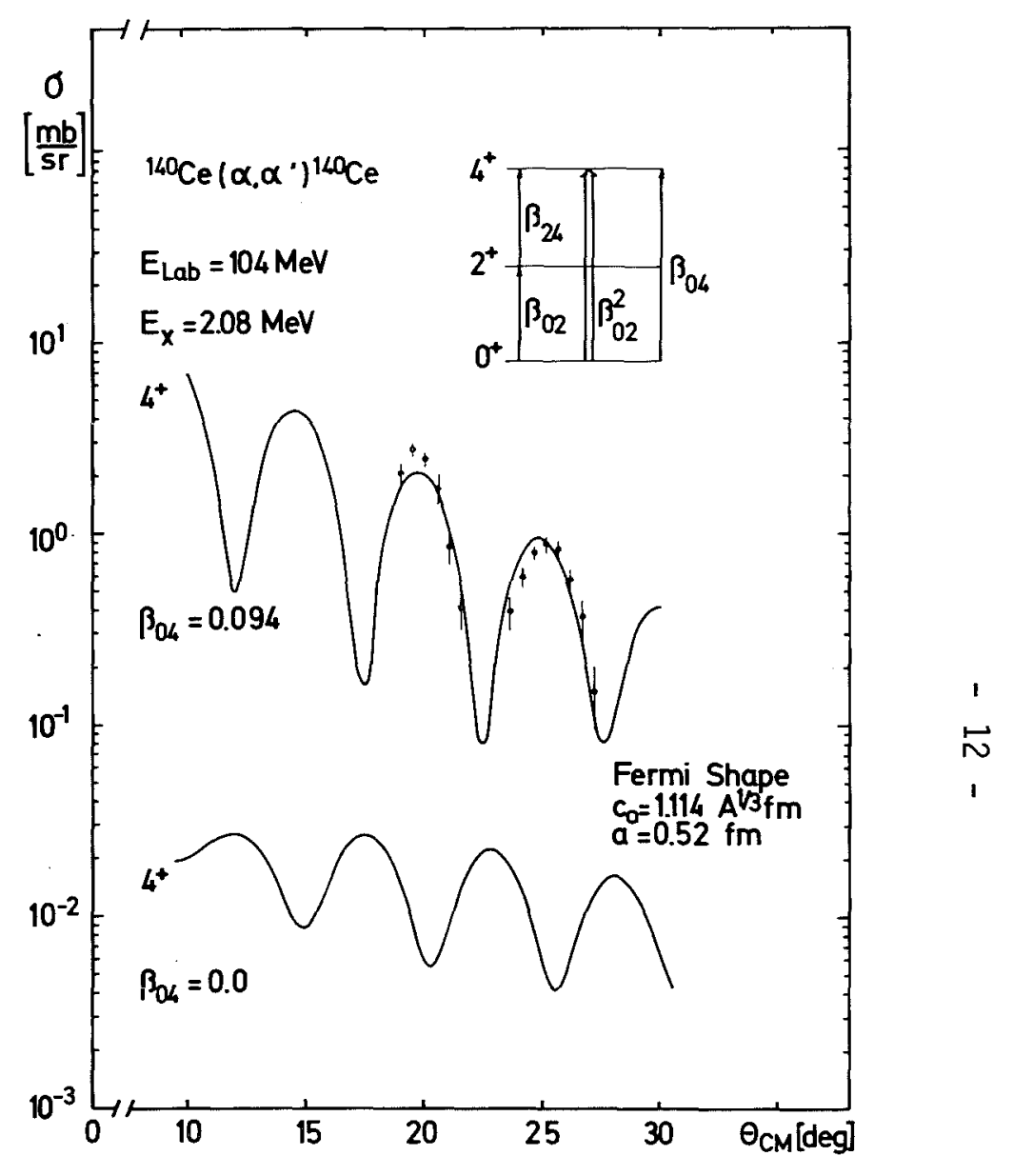

Fig. $6{ }^{140} \mathrm{Ce}\left(\alpha, \alpha^{\prime}\right){ }^{140} \mathrm{Ce}$ : Measured differential cross section for excitation of the 4 -state by inelastic $\alpha$-particle scattering and result of the coupled channel analysis.

The error bars only include the statistical error and the error of the scattering angle $\left( \pm 0.1^{0}\right)$

which was converted into a cross section error. 
It should be noted that due to the strong retardation of the decay of the $4_{1}^{+}$state of ${ }^{140} \mathrm{Ce}$ (sma11 $B_{24}$ value) double excitation of the $4_{1}^{+}$level is negligible, and consequently the choice of the not well known $\beta_{02}$ matrix element does not influence the result for $\beta_{04}$ significantly.

\section{DISCUSSION}

In tab. 1 measured $L=4$ transition rates $G_{4}=B\left(L 4 ; 0^{+} \rightarrow 4_{1}^{+}\right) / B$ s.p. for the $4_{1}^{+}$states in closed shell nuclei from the present and various other experiments are compiled.

In the case of ${ }^{60} \mathrm{Ni}$ the (e,e') result of Crannel et al. (1961) is considerably smaller than the value based on the investigation of Morinaga and Takahashi (1959), who reported the observation of the cross over transition in ${ }^{60} \mathrm{Ni}$ with a branching of $4 \times 10^{-7}$. This value ${ }^{+}$is definitely excluded by the upper limit from our conversion electron experiment. The information from spontaneous decay is now consistent with the electron scattering result and with our a-particle scattering experiment.

The discrepancy occuring for ${ }^{58} \mathrm{Ni}$ between the different $\alpha$-particle scattering analyses on the one hand and the electron scattering result on the other hand may be due to possible uncertainties arising from some approximate procedures of the analysis of that particular electron scattering experiment $^{++}$, and should not be taken too seriously. Unfortunately, there is no possibility to measure the spontaneous $4_{1}^{+} \rightarrow 0^{+}$transition in this case.

The remeasurement of the $G_{4}$-value of ${ }^{140} \mathrm{Ce}$ by $\alpha$-particle scattering as well as by the spontaneous decay was given rise to by the strong discrepancy between the former $\alpha$-particle scattering value of Baker and Tickle (1972) and the (e,e')-value of Pitthan (1973). The good agreement of the results of the measurements reported in this paper should be noted. A reanalys is of the former $\alpha$-particle scattering data on the basis of a theorem relating the moments of the interaction potential to the moments of the density distribution (Satchler 1972 a, Rebel 1976) yields nearly the same result.

F In their original communication the authors admit that the quoted value may be subject to an error due to some difficult correction procedures applied.

${ }^{++}$The value $G_{4}=2.2$ s.p.u.reported by Jarvis et al. (1965) is related to a uniform charge distribution with $R_{C}=1.2 \times A 1 / 3$. Considaring a realistic Fermi distribution $G_{4}$ has to be increased. 


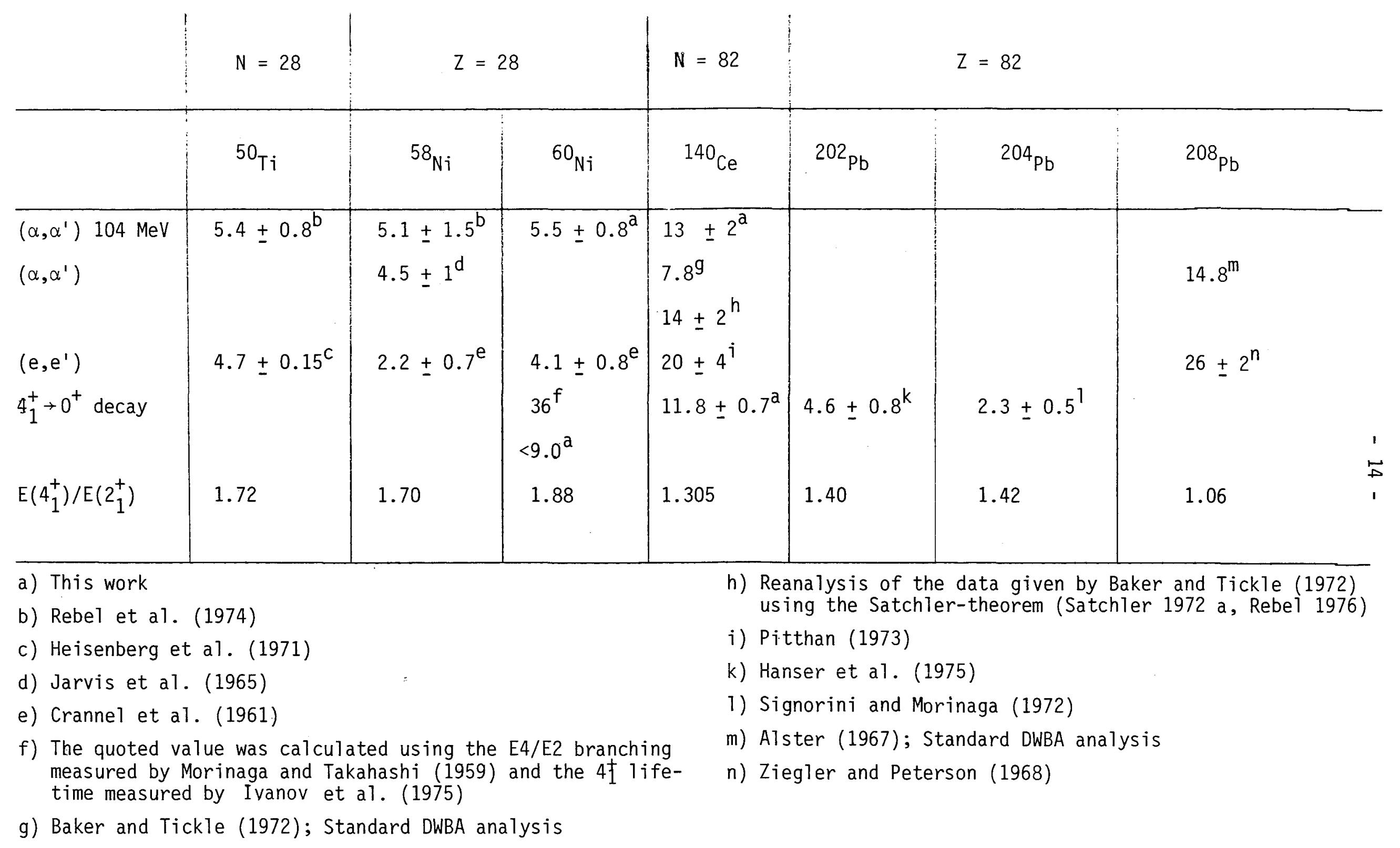

Tab. 1 Experimental $L=4$ transition rates $G_{4}=B\left(L 4 ; 0^{+} \rightarrow 4_{1}^{+}\right) / B_{\text {s.p.u. }}$ 
These findings and the fact that also the $\mathrm{B}\left(\mathrm{E2} ; \mathrm{O}^{+} \rightarrow 2^{+}\right)$value obtained in the $\left(e, e^{\prime}\right)$ experiment seems to be considerably higher than values from other experiments supports that the $G_{4}$-value reported by Pitthan (1973) is most probably too large.

When comparing scattering and spontaneous decay data one, indeed, should bear in mind that there exists a principal difference between the measured quantities, since by spectroscopy of the decay the branching of E4/E2 is determined, which is correlated to the $G_{4}$-value via the half-life of the $4^{+}$level. On the other hand by scattering experiments the transition rate is obtained directly while the branching is mostly $i 11$ determined due to the poor sensitivity of the $\alpha$-particle scattering cross sections to the $L=2$ strength $\left({ }^{\circ} \beta_{24}\right)$ of the $2_{1}^{+} \rightarrow 4_{1}^{+}$transition. However, in both cases investigated here the two types of results agree with regard to the information on the $L=4$ transition rates.

The good agreement between the mass sensitive $\alpha$-scattering data and the charge sensitive direct decay data supports that there are no differences in mass and charge transition probabilities for medium heavy nuclei. For core excited vibrational states in heavy nuclei with large neutron excess such differences may be expected as recently indicated for the octupole transition rate exciting the $3_{1}^{-}$level in ${ }^{208} \mathrm{~Pb}$. (Gils et al. 1976). In addition, there exists a clear difference between the $G_{4}$-value for the $4.32 \mathrm{MeV} 4^{+}$level (ascribed to an isoscalar surface oscillation) in ${ }^{208} \mathrm{~Pb}$ obtained from the $\left(\alpha, \alpha^{\prime}\right)$ data of Alster (1967) and the (e,e') data of Ziegler and Peterson (1968). However, the former value would certainly become larger if the measured cross sections are reanalyzed by use of more improved procedures, while the $\left(e, e^{\prime}\right)$ value is corroborated by a recent microscopic analysis of the electroexcitation of the ${ }^{208} \mathrm{~Pb}$ levels (Weber ct al. 1976).

In a11 cases discussed above the observed $L=4$ transition rates exhaust only very smal1 fractions of the energy weighted sum rule limit. There remains an appreciable amount of transition strength for the excitation of higher energetic states, possibly concentrated in a "giant resonance" (Hamamoto 1972). The measured $B(E 4)$-values of low-lying states are influenced by the virtual excitation of giant hexadecapole states of the core. The extracted values for the extrapolarization charges (accounting for the core polarization induced by neutrons and protons added to a closed core) contain some information on the 
location of the missing strength (see e.g. Satchler 1972 b). This appears to be an important aspect for experimental studies of hexadecapole transition rates of low loying levels in near closed shell nuclei.

\section{CONCLUSIONS}

The two cases of ${ }^{60} \mathrm{Ni}$ and ${ }^{140} \mathrm{Ce}$ have been regarded as experimental tests concerning the question to what extent hexadecapole transition rates extracted from $\alpha$-particle scattering can be considered to be quantitatively reliable and consistent with results from less model dependent methods. From the comparison with the model independent results from direct $4_{1}^{+} \rightarrow 0^{+}$ decay we conclude that the improved procedures based on a folding model description for $\left(\alpha, \alpha^{\prime}\right)$ scattering lead to reliable results. Discussing some selected examples (tab. 1) which may be supplemented by several other cases (e.g. in $\mathrm{Zn}$ isotopes, see Alpert et al. 1971) evidence for hexadecapole motion as being a general phenomenon in low-lying states of spherical and quasispherical nuclei is presented. Considering tab. 1 a conspicuous feature is indicated by a rough correlation between observable $L=4$ admixtures and the lowering of the $4_{1}^{+}$levels relative to the $2_{1}^{+}$levels and as compared to the vibrational model criteria. Improved phenomenological or microscopic structure models should take account of these features.

We thank Prof. Dr. G. Schatz and Prof. Dr. F. Rauch for their encouraging interest and for various communications. We are grateful to Mrs. G. Bechtold, Mr. B. Feurer and Mr. J. Rieder for their assistance during the experiments, and acknowledge the participation of Dr. K. Wisshak in an early stage of the ${ }^{60} \mathrm{Ni}$ experiments. 
APPENDIX: EXPERIMENTAL DETAILS

A DETAILS OF THE CONVERSION ELECTRON MEASUREMENT CONCERNING THE $\underline{4}_{1}^{+} \rightarrow 0^{+}$TRANSITION STRENGTH IN ${ }^{60} \mathrm{NI}$

A-1 The Spectrometer

As indicated in sect. 2 of this report we used a "mini orange" spectrometer for the attempt to detect conversion electrons from the $4_{1}^{+} \rightarrow 0^{+}$crossover transition in ${ }^{60} \mathrm{Ni}$. In this spectrometer a toroidal magnetic field produced by a set of strong permanent magnets focuses electrons of the interesting energy range from the source onto a Si(Li) detector $\left(200 \mathrm{~mm}^{2}\right.$ area $x 5 \mathrm{~mm}$ depth in the actual case). In spite of the low detection efficiency of the "mini orange" for other than the interesting radiation, problems arose from the low energy $B^{-}$-spectrum and the E2 $\gamma$-rays of the ${ }^{60}$ Co decay both being extremely intensive with respect to the weak $4_{1}^{+} \rightarrow 0^{+}$transition, and thus giving rise to pile-up events in the spectrum up to $2,5 \mathrm{MeV}$ and more. To improve the suppression of the disturbing radiation the set-up of the magnets has been separated into two equal parts (in contrast to former versions of the "mini orange"). This configuration has two advantages:

i) The distance between source and detector is enlarged (see left insert of fig. 1). This permits the use of a large central lead absorber ( $\sim 10 \mathrm{~cm}$ length) reducing the intensities of the $\gamma$-rays by as much as a factor of $5 \times 10^{-4}$.

ii) The strong toroidal magnetic field in the radial gaps between the permanent magnets (see fig. A-1) decreases with distance $R$ from the optical axis. In such a field low energy electrons are drifting towards the detector by multiple looping (fig. A-2a). However, in the region between the two parts of the magnetic arrangement (fig. A-1) a rather weak magnetic field of the same azimuthal direction but with radially increasing strength is present due to the influence of the edges of the permanent magnets. This gives rise to a backward drift (fig, A-2b) and thus to strongly reduced detection efficiency for low energy electrons.

For further reduction of pile-up events a commercial pile-up rejection system $\left.{ }^{*}\right)$ has been used eliminating pile-up events resulting from pulses with time differences larger than 150 nsec.

*) Elscint, Type CAV-N-3 

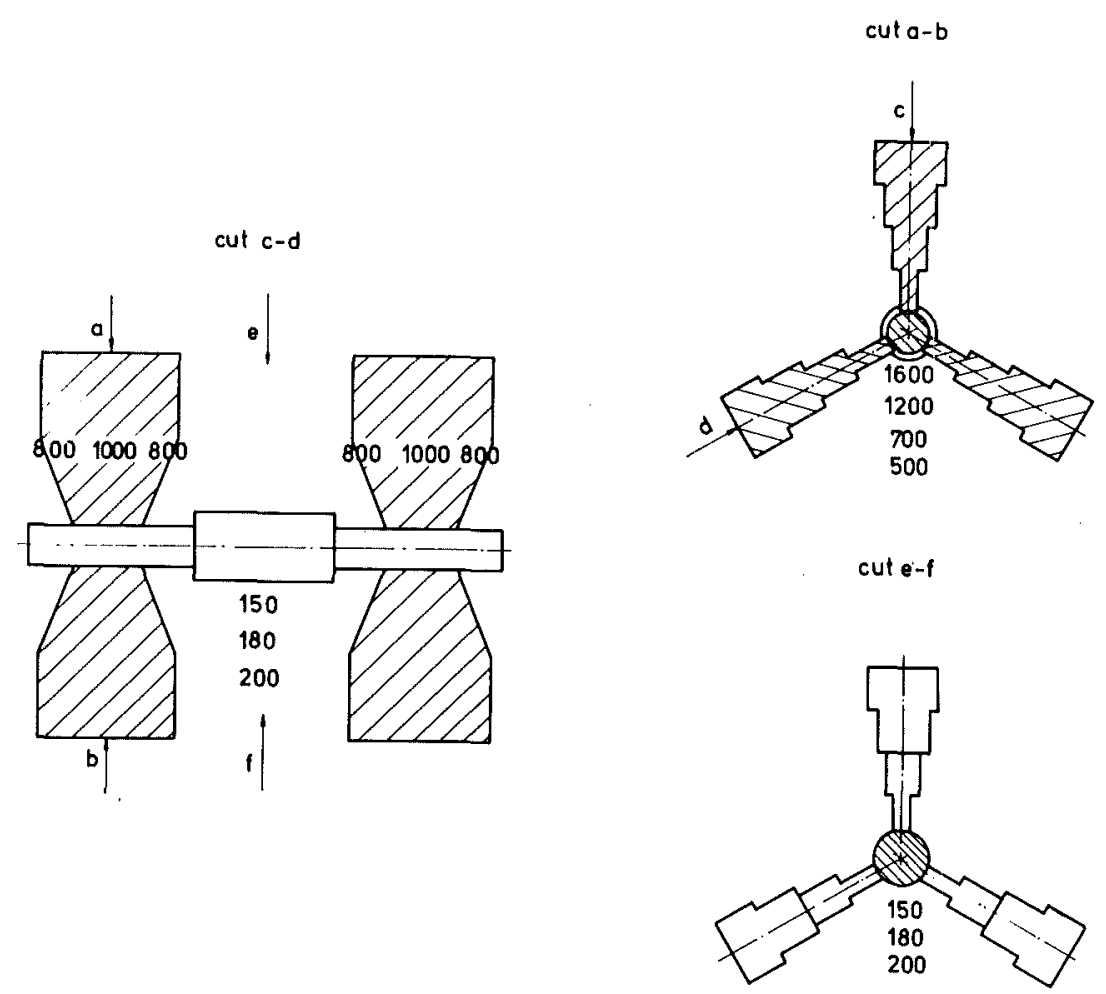

Fig. A-1: Field distribution of the magnet system measured with a Hall probe. The values are given in gauss.

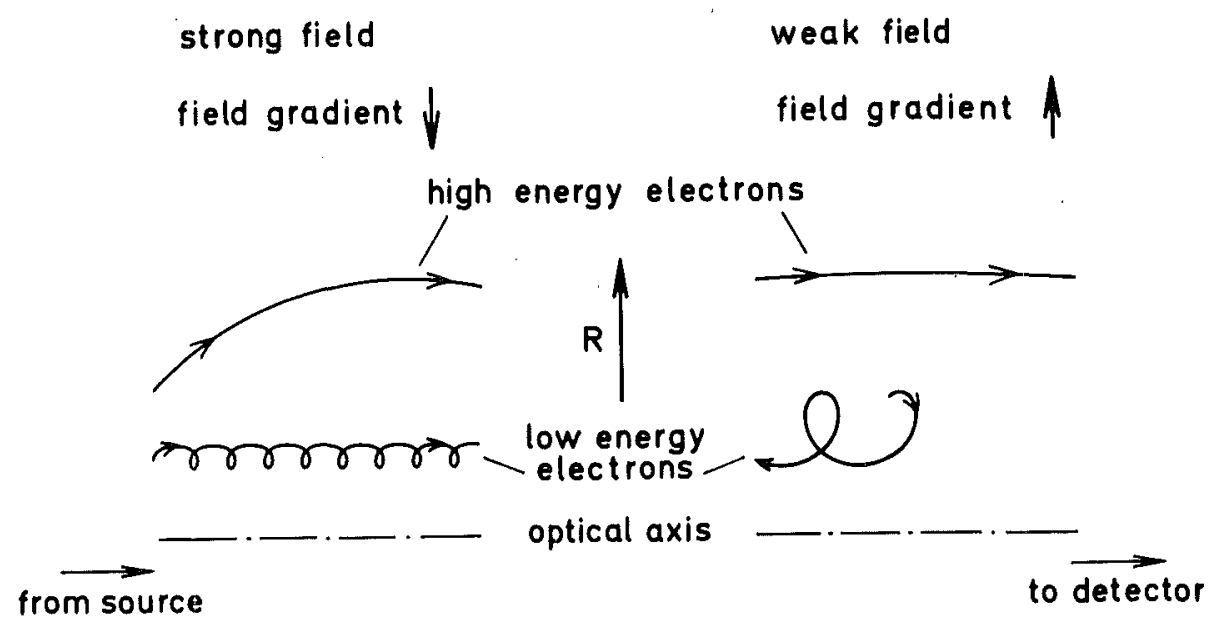

a)

b)

Fig. A-2: Trajectories of high and low energy electrons in the magnetic field of the "double mini-orange" used in the present experiment. The direction of the magnetic field points into the figure plane. 
The power of the total spectrometer set-up is demonstrated by the detection of the also very weak $2158 \mathrm{keV} 2_{2}^{+}+0^{+}$transition in ${ }^{60} \mathrm{Ni}$ clearly visible as a pronounced peak in the electron spectrum (fig. A-3). The $2158 \mathrm{keV}$ level is fed by the decay of ${ }^{60}$ Co to an amount of $1.1 \times 10^{-5}$ of the total decay rate (Camp and van Hise 1976). The conversion coefficient of this E2 transition has been found by extrapolation of the tables of Sliv and Band (1965) to be $\alpha_{k}=4.8 \times 10^{-5}$. In the present measurement the count rate for this transition was $3.5 \times 10^{-4} \mathrm{cts} / \mathrm{sec}$.

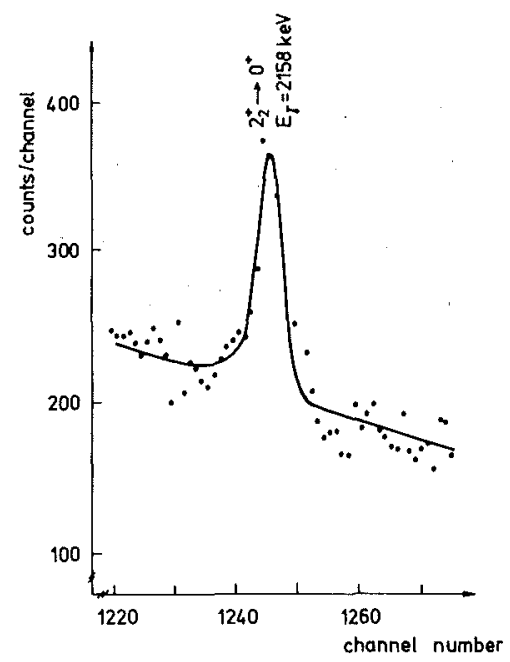

Fig. A-3: Part of the measured electron spectrum with the conversion peak corresponding to the weak $2_{2}^{+} \rightarrow 0^{+}$transition in ${ }^{60} \mathrm{Ni}\left(E_{\gamma}=2158 \mathrm{keV}\right)$. The ful1 curve results from an asymmetric Gaussian least square fit.

\section{A-2 The ${ }^{60}$ Co Source}

A neutron activated high purity co foil of $2 \mathrm{mg} / \mathrm{cm}^{2}$ thickness was used as source. After the activation the foil had been stored for several months to allow shortlived contaminant activities to decay. The content of other elements in this foil was in the order of $10^{-4}(\mathrm{Ni})$ or lower $(\mathrm{Al}, \mathrm{Ag}, \mathrm{B}, \mathrm{Cu}, \mathrm{Fe}, \mathrm{Mg}, \mathrm{Si})$. The activation of these elements produced no high energetic background in the present measurement because of short life times or low transition energies (IAEA, 1974). The source strength has been measured to be $2.96 \mathrm{mCi}$ using a Ge(Li) detector and a standard IAEA ${ }^{60}$ Co source. 


\section{A-3 The Experimental Procedure}

The conversion electron spectra were recorded into 2048 channels. The accumulated spectra were written on magnetic tape every 20000 seconds. The position and the widths of the electron peaks corresponding to $E_{\gamma}=1173 \mathrm{keV}$ and $E_{\gamma}=1332 \mathrm{keV}$ were checked for each spectrum. Some of the spectra showed peak shifts of more than two channels with respect to the mean position. These spectra have been eliminated. Thus, a total of 127 spectra could be summed up resulting in a total measuring time of 29.4 days. The width of the electronpeak from the $2158 \mathrm{keV}$ transition (fig. A-3) was a good check for the correction and summing procedure.

The energy calibration of the electron spectrometer has been performed using the conversion electrons of ${ }^{60} \mathrm{Co}$ and of a Th $(B+C+C ")$ source. The latter one is very suitable due to a strong conversion electron peak ( $E_{e}=2526 \mathrm{keV}$, $E_{y}=2615 \mathrm{keV}$ ) in the very neighbourhood of $2505 \mathrm{keV}$, the energy of the $4_{1}^{+} \rightarrow 0^{+}$transition of interest.

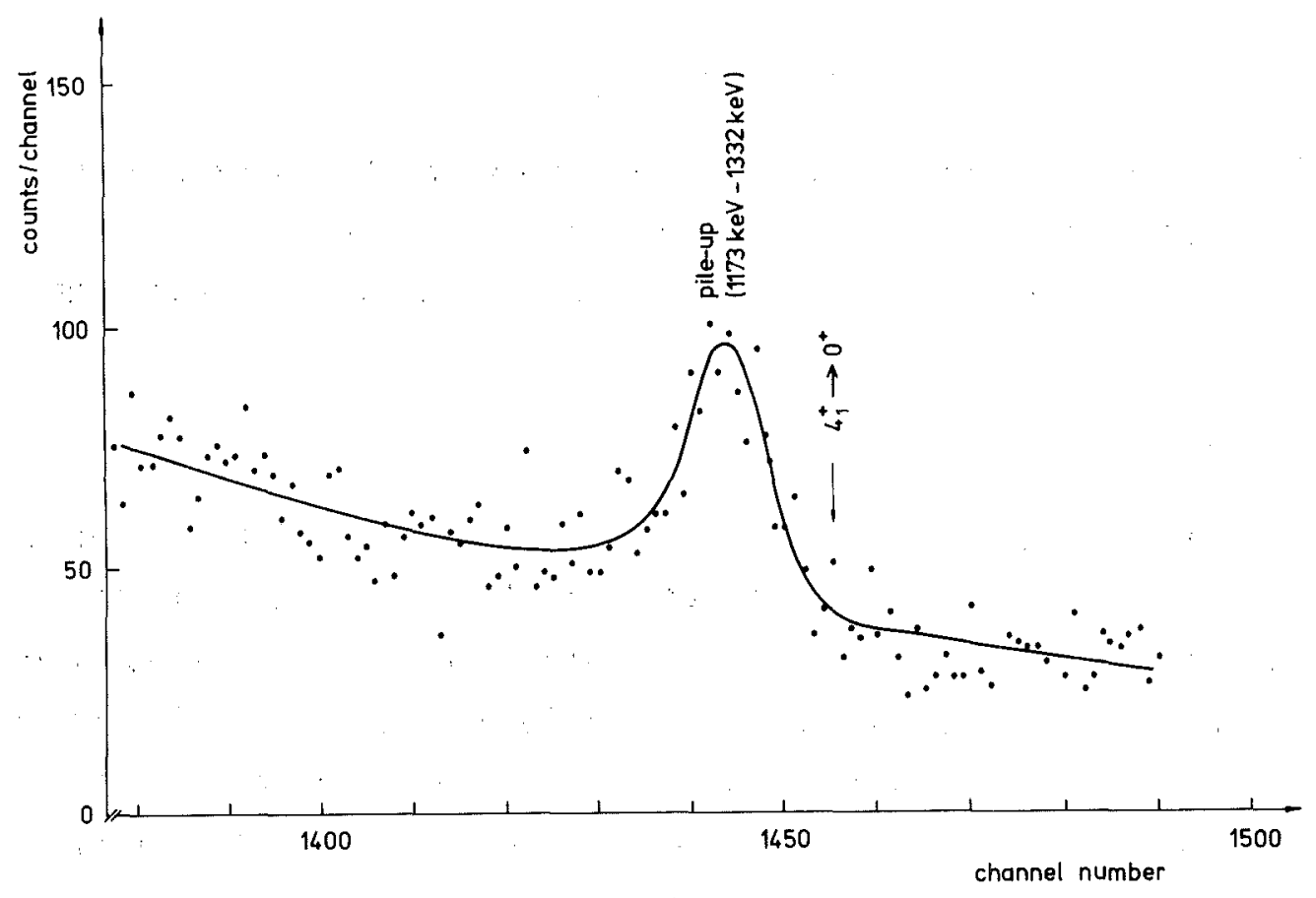

Fig. A-4: Part of the measured electron spectrum showing the pile-up peak originating from simultaneous detection of a $4_{1}^{+} \rightarrow 2_{1}^{+}$and a $2_{1}^{+} \rightarrow 0^{+}$ conversion electron. The peak has been fitted with a least square procedure. The arrow indicates the position of the expected $K$ conversion peak of the $4_{1}^{+} \rightarrow 0^{+}$transition. 
Fig. A-4 shows the region around $2505 \mathrm{keV}$ of the summed up spectrum in expanded form. Only a background of about 30 counts/channel consisting of residual pile-up events and natural background was present at the position of the expected electron peak. Adopting a peak width of $7.0 \mathrm{keV}$ (FWHM) from the width of the electron peak originating from the $2158 \mathrm{keV}$ transition, an upper limit for the area of the searched but not visible peak could be deduced.

B DETAILS OF THE MEASUREMENT OF THE $4_{1}^{+} \rightarrow 0^{+} \gamma$-RAY TRANSITION IN ${ }^{140} \mathrm{CE}$

\section{B-1 Detection Device}

The intensity of a very weak $2083 \mathrm{keV} \gamma$-ray had to be determined as accurately as possible in the presence of a competing four thousand times more intensive $487 \mathrm{keV}$ - $1596 \mathrm{keV} \gamma$-ray cascade and of a four hundred times stronger intensity of $\gamma$-rays with energies higher than $2083 \mathrm{keV}$. The geometrical arrangement for the $\gamma$-ray detection is shown in fig. B-1. The peak efficiency at $487 \mathrm{keV}$ of the coaxial $80 \mathrm{~cm}^{3} \mathrm{Ge}(\mathrm{Li})$ detector is strongly reduced by the $5 \mathrm{~cm}$ thick lead absorber between source and detector (shaded part). The $\mathrm{NaI}(\mathrm{Tl})$ anticompton annulus around the $\mathrm{Ge}(\mathrm{Li})$ detector and an annular lead shield in front of the detector reduce the background below the $2083 \mathrm{keV}$ peak originating from higher energetic $\gamma$-rays (the latter reduces the number of events in which during the absorption of a $\gamma$-quantum a photoelectron is scattered out of the sensitive volume of the detector, and a too small pulse is formed). The outer parts of the lead absorber between source and detector and the shields near the anticompton annulus shield this annulus against (truely and accidentally) coinciding $\gamma$-radiation coming directly from

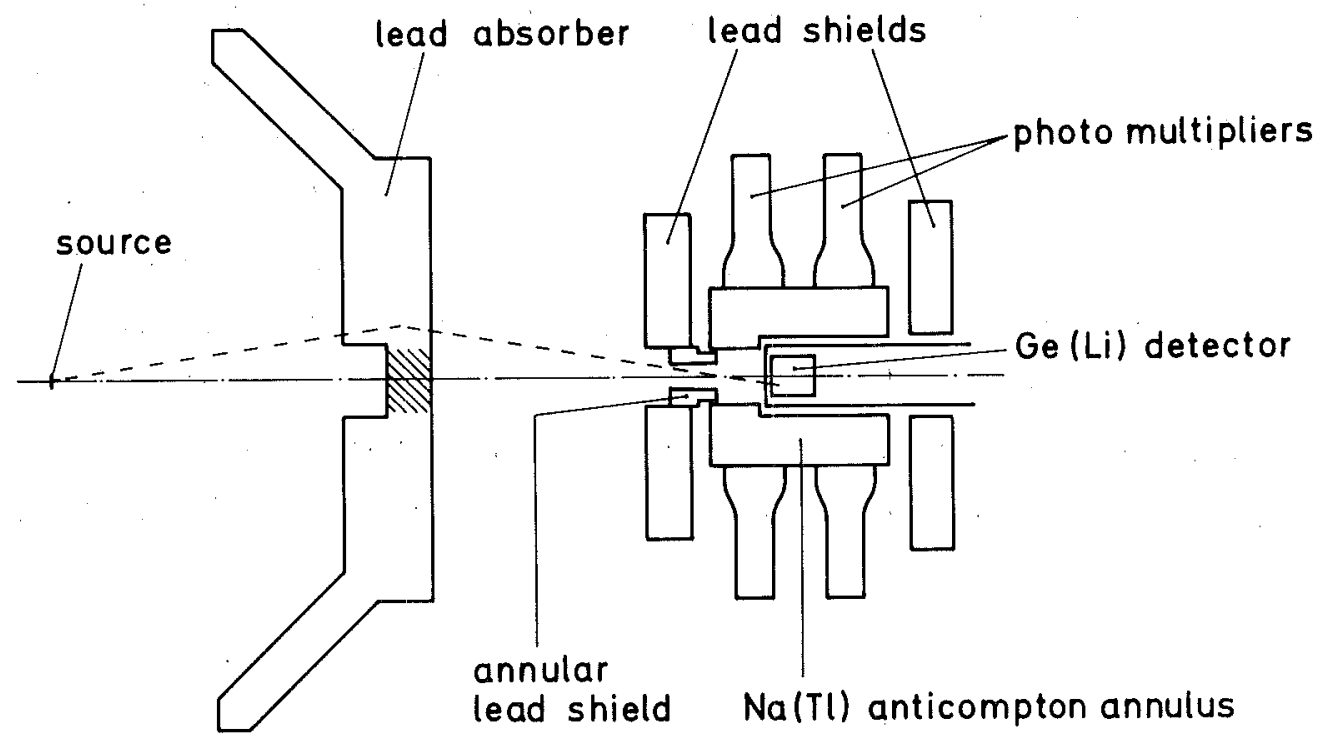

Fig. B-1: Arrangement for detecting the weak $2083 \mathrm{keV}$ cross-over transition in ${ }^{140} \mathrm{Ce}$ 
the source or scattered by parts of the apparatus. The lead thickness between source and detectors is doubled outside the radiation cone used for detection in order to prevent scattering events as indicated in fig. B-1 by the dashed line. Such events also contribute to the background below the $2083 \mathrm{keV}$ peak if higher energetic quanta are scattered.

Fig. B-2 shows the block diagram of the electronical set-up which includes a pile-up rejection circuit. ${ }^{*}$ ) The system resolution measured with the complete circuitry was $2.3 \mathrm{keV}$ (FWHM) for $1332 \mathrm{keV} \gamma$-radiation.

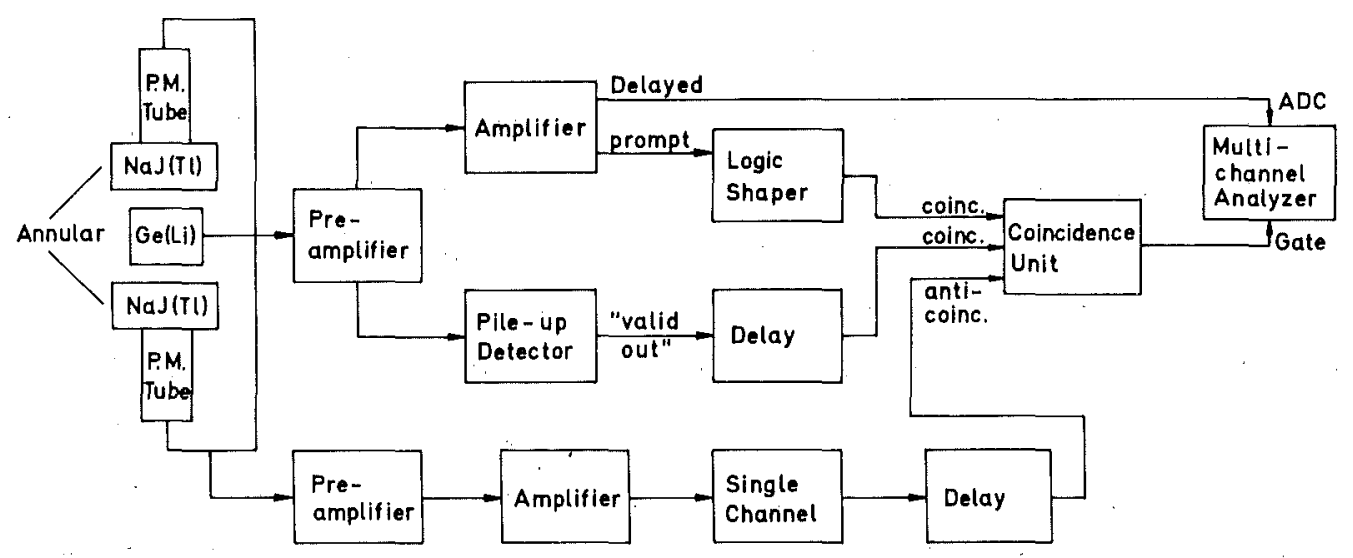

Fig. B-2: Blockdiagram of the electronical set-up

\section{B-2 Peak Analysis}

The recorded spectra were analysed using the same computer code as briefly described in sec. C-3.3. As the background in the interesting region was two times higher than the weak peak at $2083 \mathrm{keV}$, it seemed to be some what questionable whether the computer code would evaluate the peak area quite reliable in such a case. For this reason the areas of the important peaks (including calibration peaks) were additionally evaluated by hand. Fig. B-3 shows the definition of the peak area used in manual evaluation. The uncertainty of drawing the base line below the peak is estimated from the statistical variation of counts per channel near the points $A$ and $D$. The final results on $\gamma$-ray intensities are based essentially on the hand evaluation. 


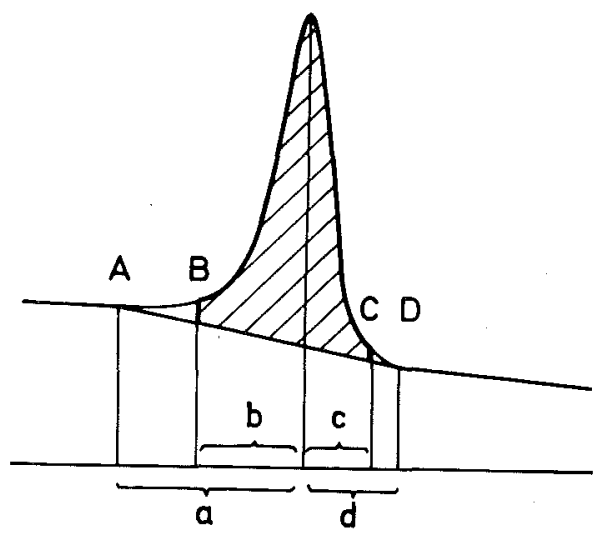

Fig. B-3: Definition of the peak area for the manual evaluation. The four distances $a, b, c, d$ are chosen properly at the beginning and then taken constant for all peaks to be evaluated. In order to reduce the error originating from the background below the peak, only the range from $B$ to $C$ is used.

\section{B-3 Check of the Assignment of the $2083 \mathrm{keV}$ Peak}

\section{B-3, 1 Check by energy}

The energy difference between the $2083 \mathrm{keV}$ - and the $1596 \mathrm{keV}$ peak has been determined precisely in order to compare it to the accurate energy value of the $487 \mathrm{keV}$ transition given in the literature. For a precise calibration the $\gamma$-rays of ${ }^{56} \mathrm{Co},{ }^{66} \mathrm{Ga}$, and ${ }^{140} \mathrm{La}$ were recorded simultaneously with the same spectrometer arrangement as used in detecting the $2083 \mathrm{keV} \gamma$-ray. The energy values of the $\gamma$-rays used for calibration have been adopted from values given by several authors (Baer et a1. 1966, Camp and Meredith 1971, Gehrke et a1. 1971, Gunnink et a1. 1968, Karlsson et a1. 1967, Phelps et al. 1970, Scott and Patter 1969, and Wild and Meyer 1970). The adopted energy values are compiled in table B-1. Fig. B-4 shows the positions and error bars of the calibration points in the range from $700 \mathrm{keV}$ to $3300 \mathrm{keV}$, if the deviation from a 1 inear energy scale fixed by the two calibration points at $816 \mathrm{keV}$ and $3273 \mathrm{keV}$ is plotted. The eye fitted solid curve represents the most probable shape of nonlinearity. The dashed curces limit the estimated range of uncertainty (corresponding to one standard deviation) of the difference in non-linearity between $1596 \mathrm{keV}$ and $2083 \mathrm{keV}$. Only this difference enters the energy check. The main $\gamma$-ray peaks of ${ }^{140} \mathrm{La}$ admixed to the calibration spectrum enabled the transfer of the calibration to the pure ${ }^{140} \mathrm{La}$ spectrum in which the $2083 \mathrm{keV}$ peak (see fig. B-6) is well seen. (For the result of the energy check see p. 7.) 
Table B-1: Adopted $\gamma$-ray energy values used for calibration

\begin{tabular}{ccc}
$\begin{array}{c}{ }^{56} \mathrm{Co} \\
(\mathrm{keV})\end{array}$ & $\begin{array}{c}{ }_{\mathrm{Ga}}^{6{ }_{\mathrm{Ga}}} \\
(\mathrm{keV})\end{array}$ & $\begin{array}{c}{ }^{140} \mathrm{La} \\
(\mathrm{keV})\end{array}$ \\
\hline $1175.11 \pm 0.06$ & $1418.90 \pm 0.08$ & $751.79 \pm 0.07$ \\
$1238.29 \pm 0.04$ & $1918.62 \pm 0.06$ & $815.83 \pm 0.06$ \\
$1360.24 \pm 0.04$ & $2189.84 \pm 0.06$ & $925.23 \pm 0.08$ \\
$1771.43 \pm 0.06$ & $2422.77 \pm 0.06$ & \\
$2015.35 \pm 0.06$ & $2751.99 \pm 0.07$ & \\
$2034.91 \pm 0.05$ & $3229.16 \pm 0.06$ & \\
$2598.57 \pm 0.06$ & & \\
$3202.19 \pm 0.06$ & & \\
$3253.64 \pm 0.06$ & & \\
$3273.18 \pm 0.06$ & & \\
\hline
\end{tabular}

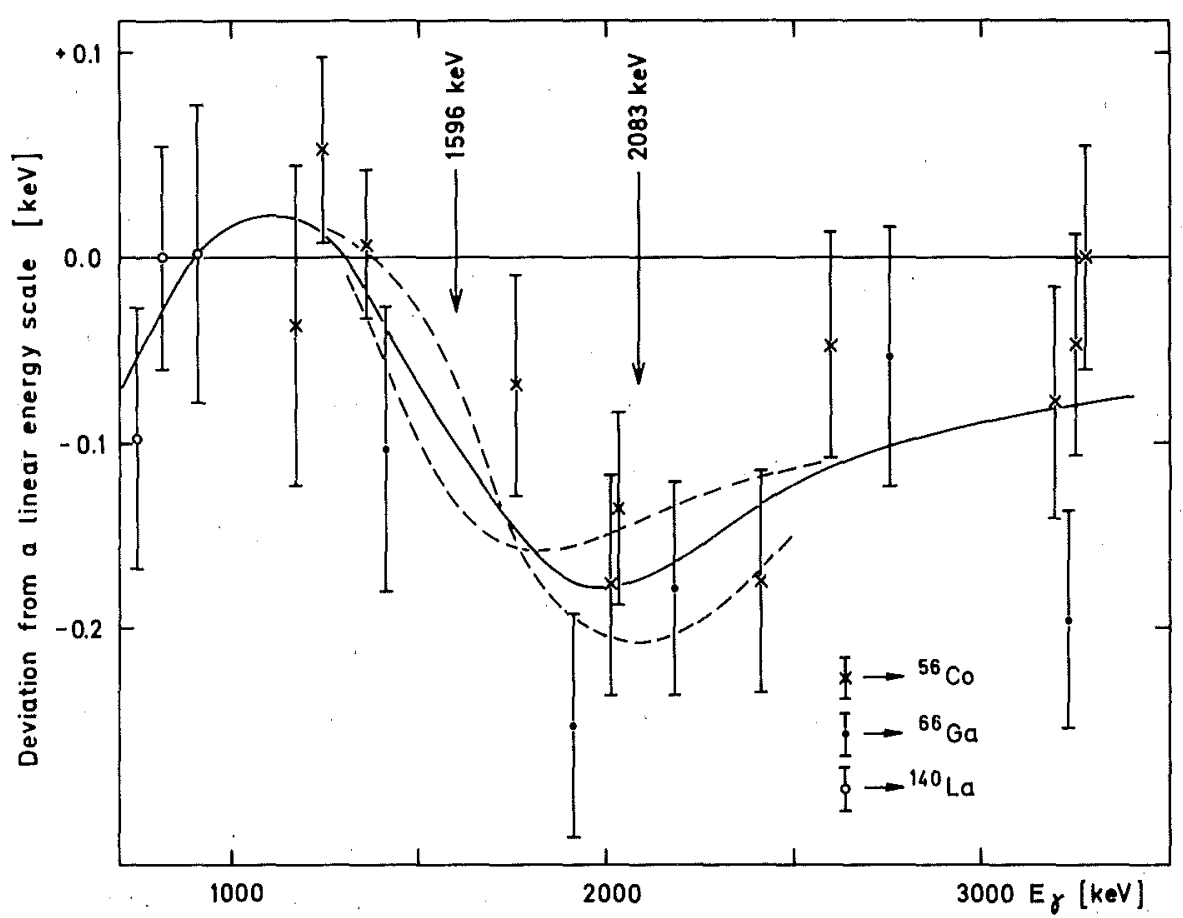

Fig. B-4: Energy calibration and non-linearity of the spectrometer used for detecting the $2083 \mathrm{keV} \gamma$-ray 


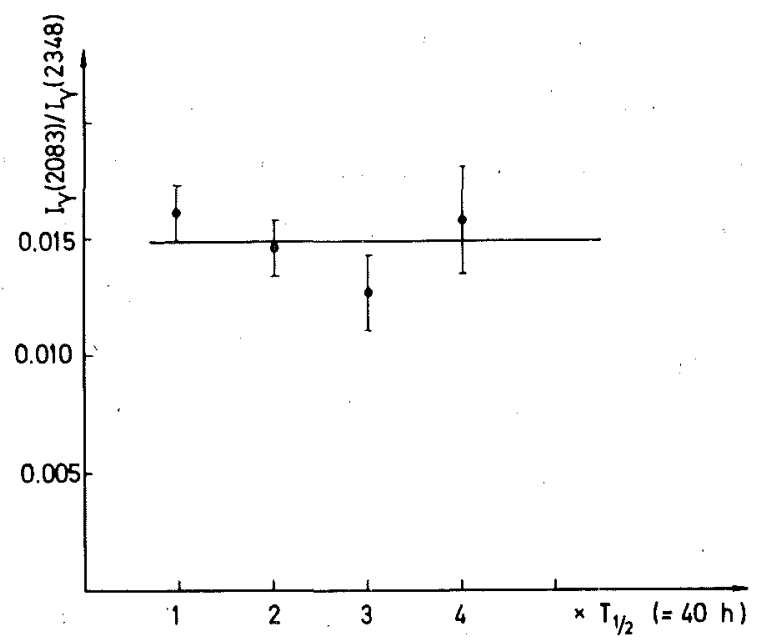

Fig. B-5: Check of the half-life of the $2083 \mathrm{keV}$ peak. The horizontal 1ine corresponds to the weighted mean value of the four measured values. The error bars represent \pm 1 standard deviation.

\section{B-3.2 Check by Half-life}

The ratio of the area of the $2083 \mathrm{keV}$ peak to that of the $2348 \mathrm{keV}$ peak which belongs to a wel1 known $\gamma$-ray transition following the decay of ${ }^{140}$ La was observed for four periods of ${ }^{140} \mathrm{La}$. In order to effect that the count rate is not too high during the first period nor too low during the last period, the source strength was doubled after the first period. It is essential for this check that the added second source was made from the same material, at the same time and with the same neutron spectrum as the first one. Fig. B-5 shows the result of this test.

\section{B-3.3 Might the $2083 \mathrm{keV}$ Peak originate from a Contamination Activity} of Similar Half-life?

Al1 clearly recognizable peaks of the ${ }^{140} \mathrm{La}$ spectrum which do not correspond to wellknown $\gamma$-ray transitions of the ${ }^{140}$ La decay (except the $2083 \mathrm{keV}$ peak!) were either background peaks from environment or they were originating from ${ }^{24} \mathrm{Na}$, the only found radioactive impurity of the sample. Therefore, if assigning the $2083 \mathrm{keV}$ peak to a radioaktive impurity, this radiation should be a dominating one of the nuclide in question. The extensive $\gamma$-catalogue of Erdtmann and Soyka (1973) contains no $\gamma$-ray the energy of which is specified as $2080 \mathrm{keV}<\mathrm{E}_{\gamma}<2086 \mathrm{keV}$ and the half $1 \mathrm{ife}$ of the mother nucleus as $10 \mathrm{~h}<\mathrm{T}_{1 / 2}<160 \mathrm{~h}$. Moreover, a radioactive contamination should be most likely an isotope of the rare earth elements or of $Y$ or Sc (third subgroup of the periodic table) which 
is produced by neutron activation. Among them there are seven isotopes with halfe-1ives between $10 \mathrm{~h}$ and $160 \mathrm{~h}:{ }^{90} \mathrm{Y},{ }^{143} \mathrm{Ce},{ }^{143} \mathrm{Pr},{ }^{153} \mathrm{Sm},{ }^{159} \mathrm{Gd},{ }^{166} \mathrm{Ho}$, and ${ }^{165} \mathrm{Er}$. All these nuclides can be excluded because their total decay energy is lower than $2 \mathrm{MeV}$ or because their most intense $\gamma$-peaks are not seen in the spectra. A dummy source (small polyethylene bag) irradiated together with the $\mathrm{La}_{2} \mathrm{O}_{3}$ samples for producing the ${ }^{140} \mathrm{La}$ sources did not emit a $2083 \mathrm{keV}$ $\gamma$-radiation. From all these facts it seems to be extremely unlikely that the $2083 \mathrm{keV} \gamma$-radiation originates from an impurity.

\section{B-4 Determination of the Intensity Ratio $I_{\gamma}(2083 \mathrm{keV}) / I_{\gamma}(487 \mathrm{keV})$}

A first, the intensity of the $2083 \mathrm{keV} \gamma$-ray relative to that of the $2522 \mathrm{keV}$ $\gamma$-ray of the ${ }^{140}$ La decay was determined instead of the really interesting ratio $I_{\gamma}(2083 \mathrm{keV}) / I_{\gamma}(487 \mathrm{keV})$ because the arrangement described in sect. B-1) was not suitable for low energy $r$-radiation. The ratio of efficiences for $2083 \mathrm{keV}$ and $2522 \mathrm{keV}$ was determined using the $\gamma$-radiation of ${ }^{56} \mathrm{Co}$ (see fig. 3 ) of the main part of this report). In a second step, the ratio $I_{\gamma}(487 \mathrm{keV}) / \mathrm{I}_{\gamma}(2522 \mathrm{keV})$ was measured separately using the same $\mathrm{Ge}(\mathrm{Li})$ detector as mentioned above without lead absorber and without compton and pile-up suppression. The ratio of the efficiencies for $487 \mathrm{keV}$ and $2522 \mathrm{keV}$, the two $\gamma$-ray energies being wide apart from each other, was determined using the $\gamma$-rays of ${ }^{22} \mathrm{Na}$ (for relative $\gamma$-ray intensities see IAEA 1970), ${ }^{56} C_{0}$ (Katou 1975), and ${ }^{166 m_{H o}}$ (Lingemann 1974). A good deal of the large energy distance from $487 \mathrm{keV}$ to $2522 \mathrm{keV}$ could be bridged by ${ }^{22} \mathrm{Na}$ for which the intensity ratio of the $511 \mathrm{keV}$ annihilation radiation $*$ ) to the $1275 \mathrm{keV} \gamma$-radiation is very precisely known. The peak efficiency for $2522 \mathrm{keV}$ is given first of all by the peak area of the $2599 \mathrm{keV} \gamma$-radiation of ${ }^{56} \mathrm{Co}_{0}$ in the measurement of $\mathrm{I}_{\gamma}\left(487 \mathrm{keV} / \mathrm{I}_{\gamma}(2522 \mathrm{keV})\right.$ as well as in the measurement of $I_{\gamma}(2083 \mathrm{keV}) / I_{\gamma}(2522 \mathrm{keV})$. An error in the literature value of the relative intensity of the $2599 \mathrm{keV}$-radiation cancels if we form finally the quotient

$$
\frac{I_{\gamma}(2083 \mathrm{keV}) / I_{\gamma}(2522 \mathrm{keV})}{I_{\gamma}(487 \mathrm{keV}) / I_{\gamma}(2522 \mathrm{keV})}=I_{\gamma}\left(2083 \mathrm{keV} / I_{\gamma}(487 \mathrm{keV})\right.
$$

*) Care was taken to evaluate correctiy the area of the somewhat broader $511 \mathrm{keV}$ peak. 
B-5 Calculation of the Enhancement and the Main Partial Errors

The enhancement of the $4_{1}^{+} \rightarrow 0^{+}$transition in ${ }^{140} \mathrm{Ce}$ is given by

$$
G_{4}=\frac{I_{\gamma}(2083 \mathrm{keV}) / I_{\gamma}(487 \mathrm{keV}) \cdot T_{1 / 2, \mathrm{s.p} .}(\mathrm{E} 4)}{T_{1 / 2, \exp }\left(4_{1}^{+}\right) \cdot\left(1+\alpha_{\text {tot }}(E 2)\right)}
$$

where $T 1 / 2$,s.p. (E4) is the single particle half-1ife of a $2083 \mathrm{keV} E 4$ transition in ${ }^{140} \mathrm{Ce}, \mathrm{T}_{1 / 2, \exp }\left(4_{1}^{+}\right)$the measured half-life of the $4_{1}^{+}$-state in ${ }^{140} \mathrm{Ce}$, and $\alpha_{\text {tot }}(E 2)$ the total conversion coefficient of the $487 \mathrm{keV}$ E2 transition in ${ }^{140} \mathrm{Ce}$. $T_{1 / 2, s . p .}(E 4)$ was calculated from the formula given by Wapstra et a1. (1959) to be $1.62 \cdot 10^{-4} \mathrm{~s}$. For $\alpha_{\text {tot }}(\mathrm{E} 2)$ we adopted a value of $0.022 \pm 0.002$ from the measurements quoted by Peker et a1. (1974). For the values of $T_{1 / 2, \exp }\left(4_{1}^{+}\right)$and $I_{\gamma}(2083 \mathrm{keV}) / I_{\gamma}(487 \mathrm{keV})$. see page 9 of the main part of this report.

The largest partial error $\left(4.8 \%\right.$ ) in determining the $G_{4}$-value originates from the determination of the $2083 \mathrm{keV}$ peak area. Fig. B-6 shows the recorded peak (summed over all runs) and the limits of its area corresponding to the definition given in fig. B-3) as well as the (estimated) uncertainty of the base line. The second important partial error $(2.9 \%)$ is the overall calibration uncertainty, i.e. the error of the double ratio

$$
\frac{\varepsilon(2083) / \varepsilon(2522)}{\varepsilon^{\prime}(487) / \varepsilon^{\prime}(2522)}
$$

where $\varepsilon$ means the $\gamma$-efficiency of the measuring arrangement with lead absorber and $\varepsilon^{\prime}$ the efficiency of the simple Ge(Li) detector arrangement without lead absorber.

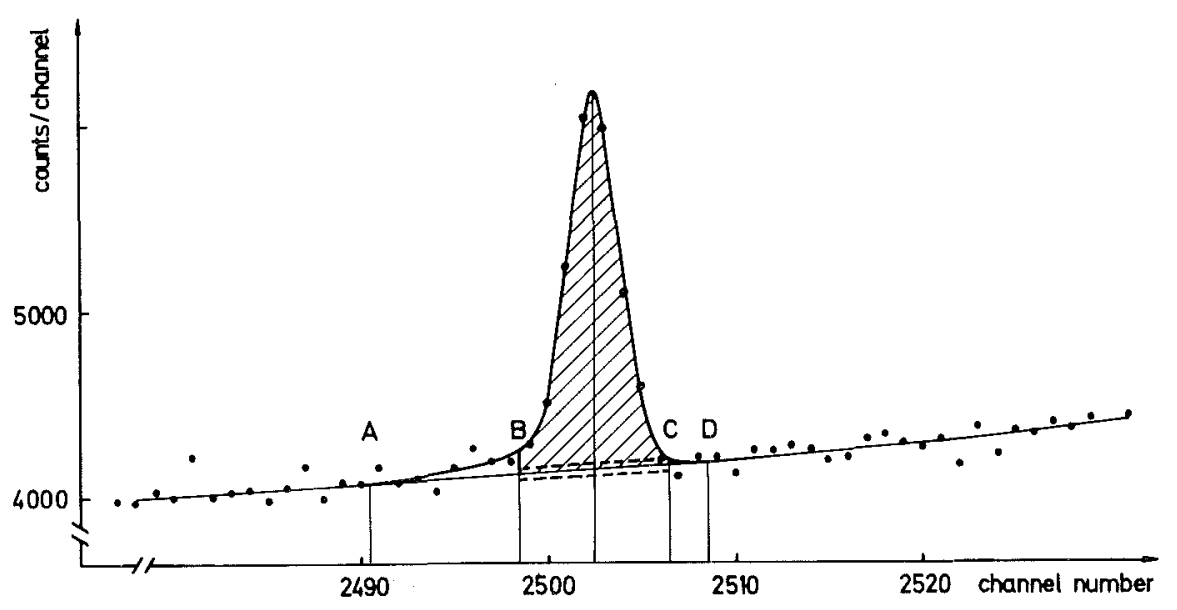

Fig. B-6: The $2083 \mathrm{keV}$ peak from which we deduced the $4_{1}^{+} \rightarrow 0^{+}$enhancement. The dashed lines mark the estimated uncertainty (one standard deviation) of the base line. 
B-6 Additional Spectroscopic Results

${ }^{140}$ La may be suitable for energy and efficiency calibration of $\gamma$-ray spectrometers. For the $\gamma$-rays below $1 \mathrm{MeV}$ there exist precise energy measurements using crystal spectrometers and magnetic conversion electron spectrometers (Bear et a1. 1966; Karlsson et a1. 1967). However, the energy values for the $1596 \mathrm{keV}$, $2348 \mathrm{keV}$, and $2522 \mathrm{keV}$ transitions which also may be useful for calibration purposes are less reliablely known. (For a summary see Peker et a1. 1974; see also Gunnink et al. 1968). In addition, more reliable values of the relative $\gamma$-ray intensities are desirable $\left.{ }^{*}\right)$. The measurements with our carefully calibrated spectrometer have yielded new values with small error statements which are listed in table B-2. Finally, the precise energy value of the $4_{1}^{+} \rightarrow 0^{+}$-transition in ${ }^{140} \mathrm{Ce}$ measured in this work is given in this table.

Table B-2: Additional spectroscopic results on the $\gamma$-radiation accompanying the ${ }^{140}$ La decay

\begin{tabular}{ccc} 
Transition (keV) & Precise energy value (keV) & Relative intensity \\
\hline 329 & & $22.0 \pm 0.8$ \\
487 & $48.6 \pm 1.2$ \\
752 & $4.68 \pm 0.11$ \\
816 & $24.9 \pm 0.6$ \\
1596 & $1596.34 \pm 0.08$ & 100. \\
2348 & $2348.06 \pm 0.09$ & $0.857 \pm 0.023$ \\
2522 & $2521.57 \pm 0.09$ & $3.50 \pm 0.09$ \\
2083 & $2083.46 \pm 0.10$ & \\
\hline
\end{tabular}

*) The smal1 errors of the relative $\gamma$-ray intensities given by Kalinnikov et al. (1970) do not correspond to the moderate accuracy stated in the text of their work. Moreover, the measured value for the strong $487 \mathrm{keV}$ transition does not agree well with the results of several other authors (see Peker et al. 1974). 


\section{DETAILS OF THE $\left(\alpha, \alpha^{\prime}\right)$ SCATTERING MEASUREMENTS}

C-1 Experimental Arrangement

The $\left(\alpha, \alpha^{\prime}\right)$ scattering experiments on ${ }^{60} \mathrm{Ni}$ and ${ }^{140} \mathrm{Ce}$ were performed at the $\alpha$ particle beam with a nominal energy of $104 \mathrm{MeV}$. The beam was monochromized and focussed onto the target which was mounted in the center of a $1300 \mathrm{~mm}$ diameter scattering chamber. The angle between beam direction and geometrical axis of the scattering chamber was determined to be $0.2 \pm 0.1$ degrees. Four $\mathrm{Si}$ detectors of $4 \mathrm{~mm}$ thickness operated at $-20^{\circ} \mathrm{C}$ were mounted with a fixed angular distance between each other on a rotatable arm inside the scattering chamber. The energy resolution proved to be between 140 and $160 \mathrm{keV}$. For the calculation of absolute cross sections the beam current was integrated by means of a Faraday cup.

$\mathrm{C}-2$ The ${ }^{60} \mathrm{Ni}$ Experiment

The target for this experiment was a $\mathrm{Ni}$ foil, enriched to $99 \%$ of ${ }^{60} \mathrm{Ni}$. The target thickness was $5 \mathrm{mg} / \mathrm{cm}^{2}$.

The energy calibration of the spectra was performed using the elastically scattered $\alpha$ particles and the transitions to the $2_{1}^{+}$and $3_{1}^{+}$levels of ${ }^{60} \mathrm{Ni}$.

The peak areas of the transitions were calculated using a least squares fit routine which approximates the shape of the peaks by asymmetric Gaussian curves . The quality of the fit as well as the background correction was checked via an interactive facility. The fit procedure was done simultaneously for the $0^{+}, 2_{1}^{+}, 4_{1}^{+}$and $3_{1}^{-}$transitions.

C-3 The ${ }^{140}$ Ce Experiment

\section{C-3.1 Target-Preparation}

The target was prepared by a sputtering technique. A pellet of $50 \mathrm{mg} \mathrm{CeO}_{2}$ powder, enriched to $99 \%$ of ${ }^{140} \mathrm{Ce}$ with $0.2 \% \mathrm{Zn}$ as the main contaminant, was pressed and deposed into a graphite crucible. The $\mathrm{CeO}_{2}$ was bombarded with argon ions accelerated to $10 \mathrm{keV}$. It turned out that the sputtering yield of $\mathrm{CeO}_{2}$ is very low (about 1 atom/10 ions, that is 40 times smaller than for Pt) (Sletten and Knutsen 1972). It was impossible to use backings of Be or C foils $\left(\sim 80 \mu \mathrm{g} / \mathrm{cm}^{2}\right)$ because they were rapidly destroyed by the sputtered atoms. So the target material was sputtered onto a $\mathrm{KCl}$ layer. The graphite crucible with the target 


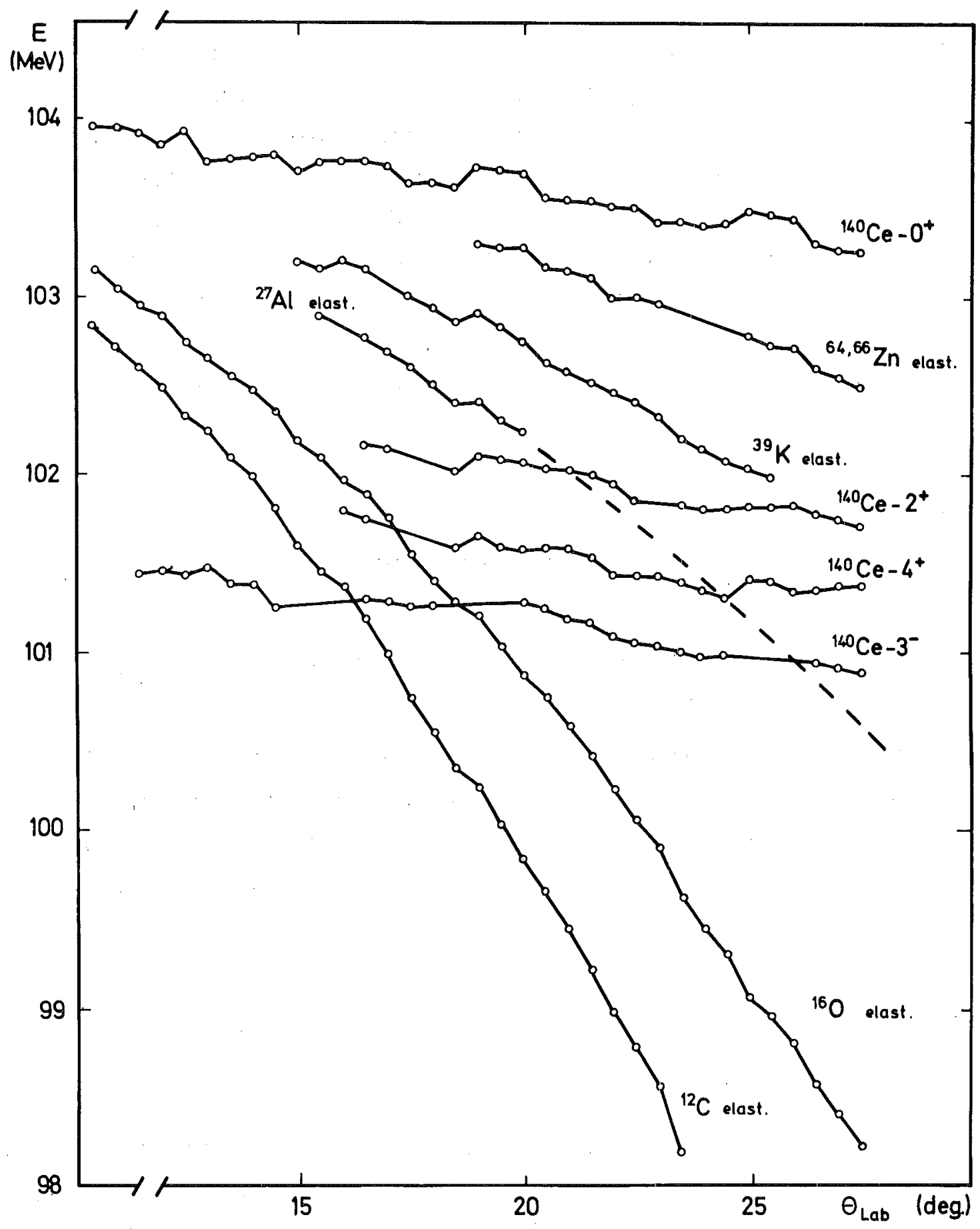

Fig. C-1: Experimental kinematic curves of ${ }^{140} \mathrm{Ce}$ and target impurity peaks in the $\left(\alpha, \alpha^{\prime}\right)$ scattering spectra. Extrapolation of the ${ }^{27}$ A1 curve is marked by dashes indicating the overlap with the ${ }^{140} \mathrm{Ce} 4_{1}^{+}$peak near 24 degrees. 


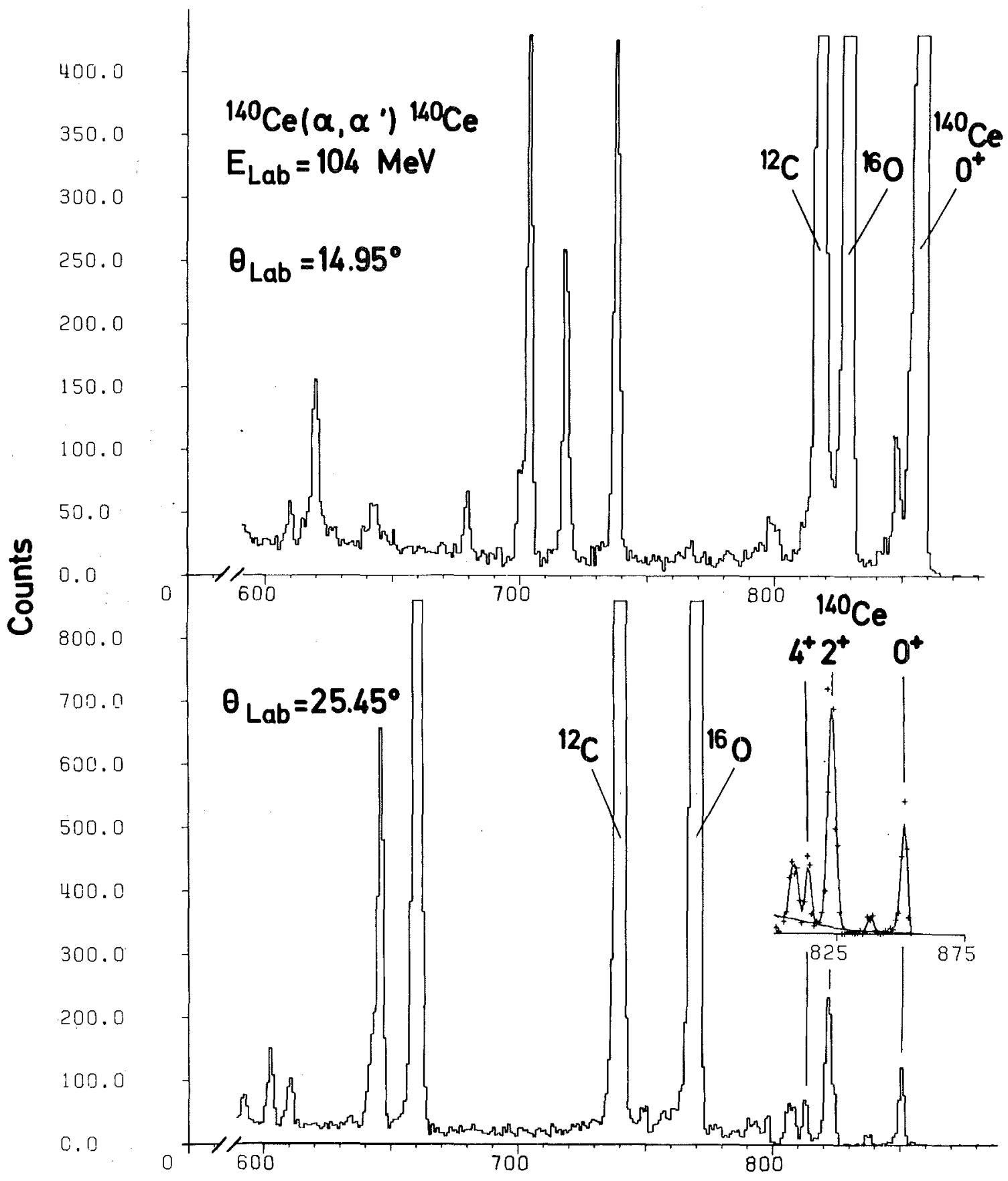

Fig. C-2: Spectra of $\alpha$-particles scattered from the ${ }^{140} \mathrm{CeO}_{2}$ target. The upper example demonstrates the overlap of the $2^{+}$and $4_{1}^{+}$peak by dominating contamination peaks. The lower spectrum was taken at a more favourable scattering angle. The inset shows the result of the computer analysis. The $2^{+}$peak is accompanied at the high energy side by a smal1 $39 \mathrm{~K}$ peak. 
powder was rotated to get a homogeneous deposition of $\mathrm{CeO}_{2}$. After 20 hours of sputtering time, using a mean beam current of $0.5 \mathrm{~mA}$, a self-supporting $\mathrm{CeO}_{2}$ foil of $1 \mathrm{~cm}^{2}$ area was obtained after the $K C l$ layer had been dissolved in water. The ${ }^{140} \mathrm{Ce}$ content of the target was determined to $(0.48 \pm 0.1) \mathrm{mg} / \mathrm{cm}^{2}$ via the elastic scattering cross section of ${ }^{16} 0$ (Hauser et a]. 1968). Due to the fabrication process, the target foil was contaminated by various elements.

\section{C-3.2 Identification of the Peaks}

Based on an external energy calibration by a separate measurement of the elastic and inelastic scattering on ${ }^{12} \mathrm{C}$, the energies of all distinguishable peaks in the most upper part of the spectra were plotted against the scattering angle (fig, C-1). Peak identification was accomplished unambiguousiy by comparision with calculated kinematic curves. Besides the ${ }^{140} \mathrm{Ce}$ peaks, contamination peaks originating from elastic scattering on ${ }^{12} \mathrm{C},{ }^{16} 0,{ }^{27} \mathrm{Al},{ }^{39} \mathrm{~K}$, and ${ }^{64,66_{\mathrm{Zn}}}$ were present. It should be noted that a peak belonging to ${ }^{35,37} \mathrm{Cl}$, as expected from the target fabrication process, was not found in the spectra. The ${ }^{140} \mathrm{Ce} 4_{1}^{+}$and $2_{1}^{+}$peaks, clearly seen in the spectrum measured at $\theta_{\text {Lab }}=25,45^{\circ}$ (fig, $C-2$ ), overlap with contamination peaks at several angle settings, as can be seen from fig. C-1. An especially unfavourable case $\left(\theta_{L a b}=14.95^{\circ}\right)$ is demonstrated in fig. C-2. In other cases the overlapping leads to separable doublets.

\section{C-3.3 Analysis of the Peaks}

The peak areas were fitted by a computer code. The first part of the code defines roughly a smoothened background which is improved by an iteration procedure in the second part. The mathematical form of the peaks was that of an asymmetrical Gaussian distribution. The program was able to separate multipletts of up to five overlapping peaks. Fig. C-3 shows the cross sections obtained by the computer processing. Unfortunately, the computer results (circles) do not well fit a smooth curve. Plots of the computer defined background showed that the peak form chosen was unable to fit a small satellite in the very neighbourhood of a hundred times stronger dominating peak. Therefore, the ${ }^{140} \mathrm{Ce} 4_{1}^{+}$peaks at 18.45 and 18.95 degrees were reanalysed by hand (squares in fig. $(-3)$. Generally, in separating overlapping peaks of comparable strength, computer processing surpassed evaluation by hand. The three points from computer analysis at $23.45,23.95$ and 24.45 degrees which lie obviously too high were found to be superimposed by the ${ }^{27} \mathrm{Al}$ impurity peak (fig, C-1). In order to 


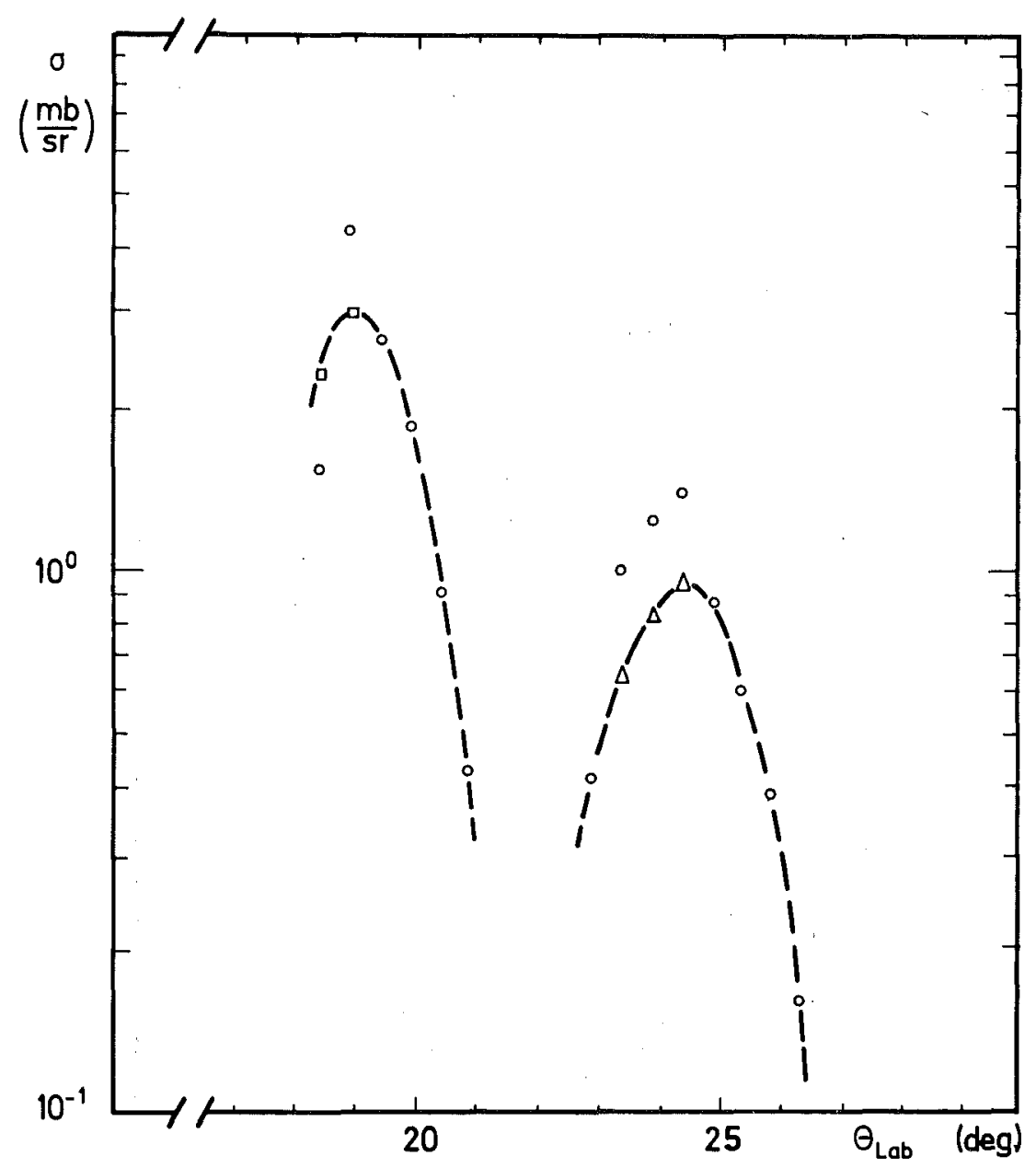

Fig. C-3: Differential scattering cross section of ${ }^{140} \mathrm{Ce}\left(4_{1}^{+}\right.$state) obtained by

computer analysis (circles) manual evaluation (squares) after subtracting the superimposing impurity peak (triangles). The dashed line connects the points used for the coupled channel analysis.

correct these points, the relative scattering cross section of aluminum (ground state) at smaller and at larger scattering angles was plotted (fig. C-4) and eye fitted by a curve parallel to the elastic ${ }^{26} \mathrm{Mg}$ and ${ }^{28} \mathrm{Si}$ scattering cross sections (Hauser et al. 1968). In fig. C-3, the triangles mark the corrected values. 


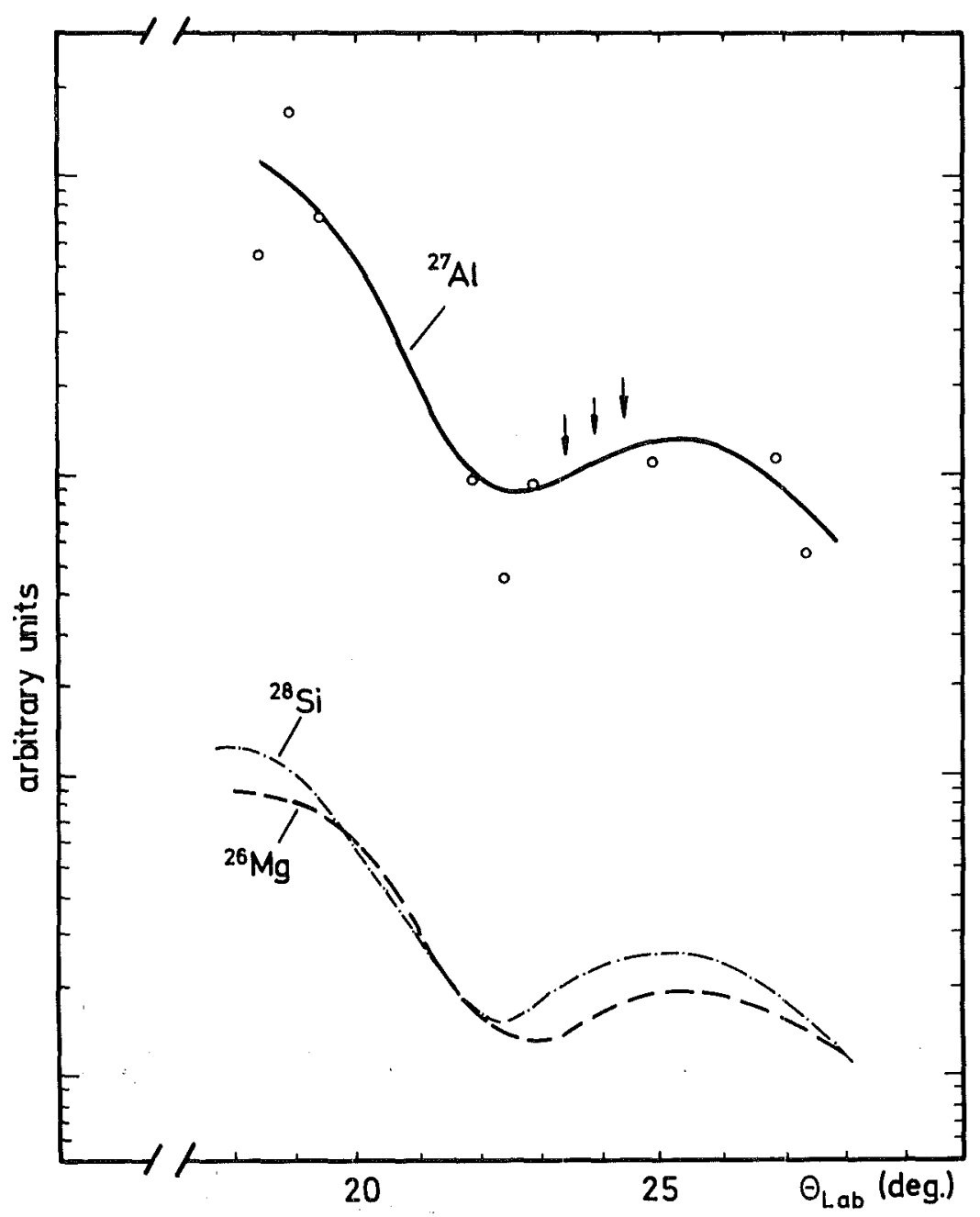

Fig. C-4: Relative elastic scattering cross section of ${ }^{27} \mathrm{Al}$ (circles). In drawing the interpolation curve (full line) the cross section was assumed to be proportional to the ${ }^{26} \mathrm{Mg}$ and ${ }^{28} \mathrm{Si}$ cross sections known from earlier published measurements (dashed 1 ines). The ${ }^{27} \mathrm{Al}$ cross section values needed to correct the ${ }^{140} \mathrm{Ce} 4_{1}^{+}$cross section at $\theta=23.45,23.95$ and 24.45 degrees are indicated by arrows. 


\section{REFERENCES}

Alpert, N., Alster, J., Martens, E.J., and Pickles, W., 1971, Phys. Rev. C4, 1230

Alster, J., 1967, Phys, Lett. 25B, 459

Baer, H.W., Reidy, J.J., Wiedenbeck, M.L., 1966, Nucl. Phys. 86, 332

Baker, F.T. and Tickle, R., 1972, Phys. Rev. C5, 182

Bernstein, A.M., 1969, Advances in Nuclear Physics, vo1. 3, ed. M. Baranger and E. Vogt (New York: Plenum Press) p. 325

Camp, D.C., and van Hise, J.R., 1976, Phys. Rev. C14, 261

Camp, D.C., and Meredith, G.L., 1971, Nuc1. Phys. A166, 349

Crannel, H., Helm, R., Kenda11, H., Oeser, J., Yearian, M., 1961, Phys. Rev. $\underline{123}, 923$

de Jager, C.W., de Vries, H., and de Vries, C., 1974, Atomic and Nuclear Data Tab. 14,479

Erdtmann, G., and Soyka, W., 1973, Report Jü1-1003-AC

Gehrke, R.J., Cline, J.E., and Heath, R.L., 1971, Nuc1. Inst. Meth. 91, 349

Gils, H.J., Rebe1, H., Nowicki, G., Ciocanel, A., Hartmann, D.,

Klewe-Nebenius, H., and Wisshak, K., 1975 a, Journal Phys. G (Nuc1. Phys.) 1, 344

Gils, H.J. and Rebe1, H., 1975 b, Z. Phys. A274, 259

Gils, H.J. Rebel, H., Buschmann, J., Klewe-Nebenius, H., Nowicki, G.P., and Nowatzke, W., 1976, Z. Phys. A279, 55

Goswami, A. and Lin, L., 1972, Phys. Lett: 42B, 310

Gunnink, R., Meyer, R.A., Niday, J.B., and Anderson, R.P., 1968, Nuc7. Inst. Meth. 65,26

Hamamoto, J., 1972, Nuc1. Phys. A196, 101

Hanser, A., Wisshak, K., Klewe-Nebenius, H., and Rebel, H., 1975, Phys.

Rev. $\mathrm{C} 12,338$

Hauser, G., Löhken, R., Rebe1, H., Schatz, G., Schweimer, W., and Specht, J., 1968, Phys. Lett. 27B, 220

Heisenberg, J., McCarthy, J.S., and Sick, J., 1971, Nuc1. Phys. A164, 353 
IAEA, 1970, recommended nuclear data

IAEA, 1974, Handbook on Nuclear Activation Cross Sections, Vienna

Ivanov, M.A., Lemberg, I.Kh., Mishin, A.S., Peker, L.K., and Chuganov, I.N., 1975, Isv. Ak. Nauk., Fiz. Ser. 39, 108 (Nr. 8)

Jarvis, 0.N., Harvey, B.G., Hendrie, D.L., Bussière de Nercy, An, Mahoney, J., 1965, Nuc1. Phys. 72, 97

Kalinnikov, V.G., Ravn, K.I., Hansen, H.G., and Lebedev, N.A., 1970, Bul1.

Akad. Sci. USSR, Phys. Ser. 34,815

Karlsson, S.E., Svahn, B., Pettersson, H., Malmsten, G., De Aisenberg, E.Y., 1967, Nuc1. Phys. A100, 113

Katou, T., 1975, Nuc1. Inst. Meth. 124, 257

Kuo, T.T.S., and Brown, G.E., 1966, Proc. Int. Nucl. Phys. Conf. Gatlinburg, (Academic Press, N.Y. 1967) p. 526

Lesser, P.M.S., Cline, D., Kalbach-Cline, C., and Bahnsen, A., 1974, Nucl.

Phys. A223, 563

Lingeman, E.W.A., de Boer, F.W.N., and Meijer, B.J., 1974, Nucl. Inst. Meth. 118,609

Morinaga, H. and Takahashi, K., 1959, J. Phys. Soc. Japan 14, 1960

Nagao, M. and Torizuka, Y., 1971, Phys. L. 37B, 383

Peker, L.K., Sigalov, V.M., and Kharitonov, Y.I., 1974, Nucl. Data Sheets 12, 343

Phelps, M.E., Samarantites, D.G., Winn, W.G., 1970, Nucl. Phys. A149, 647

Pitthan, R., 1973, Z. Phys. 260, 283

Rebel, H., Löhken, R., Schweimer, G.W., Schatz, G., and Hauser, G., 1972 a,

Z. Phys. 256, 258

Rebel, H., Schweimer, G.W., Schatz, G., Specht, J., Löhken, R., Hauser, G., Habs, D., and Klewe-Nebenius, H., 1972 b, Nucl. Phys. A182, 145

Rebe1, H., Hauser, G., Schweimer, G.W., Nowicki, G., Wiesner, W., Hartmann, D., 1974, Nuc1. Phys, A218, 13

Rebe1, H., 1976, Z. Phys. A277, 35

Ronsin, H., Bezzit, P., Delaunay, J., Bellini, R., Fodor, I., and Fouan, J.P., 1973, Nuc1. Phys: A207, 577 
Satchler, G.R., 1972 a, Journ. Math. Phys. 13, 1118

Satchler, G.R., 1972 b, Comm. Nucl. Particle 5, 145

Scott, H.L., and van Patter, D.M., 1969, Phys. Rev. 184, 1111

Signorini, C. and Morinaga, H., 1972, Phys, Lett. 40B, 549

Sletten, G., and Knutsen, P., 1972, Nuc1. Inst. Meth. 102, 459

Sliv, L., and Band, I.M., 1965, Alpha-, Beta-, and Gamma-Ray Spectroscopy, ed. K. Siegbahn, North Holland Publishing Company, Amsterdam, p. 1639

Tamura, T., 1965, Nucl. Phys. 73, 81

Tamura, T., 1966, Progr. Theoret. Phys. Supp 1. 37, 38, 198

van Klinken, J., Feenstra, S.J., Wisshak, K., and Faust, H., 1975, Nucl. Inst. Meth. 130, 427

Wapstra, A.H., Nijgh, G.J., and van Lieshout, R., 1959, Nuclear Spectroscopy Tables, p. 71, Amsterdam, North Holland Publishing Company Weber, E., Knüpfer, W., Grecksch, E., Huber, M.G., 1976, Phys. Lett. 65B, 189 Wi1d, J.F., and Meyer, R.A., 1970, Bu11. Am. Phys, Soc, 15, 62 Ziegler, J.F., and Peterson, G.A., 1968, Phys. Rev. 165, 1337 